\title{
The potential for water stewardship partnership in Kenya
}

\author{
Kasiti Felix Isundwa ${ }^{1} \cdot$ Khaldoon A. Mourad $^{1,2}$ (1) \\ Received: 16 October 2018 /Revised: 21 January 2019 / Accepted: 7 May 2019 /Published online: 13 June 2019 \\ (C) The Author(s) 2019
}

\begin{abstract}
Water resources face risks due to water use stress and water scarcity. Collective and integrated actions by different institutions and stakeholders are needed to reduce future water risks. This paper aimed to assess the potential for a water stewardship partnership in River Nzoia Basin to reduce future water risks facing the ecosystem, agriculture, and other sectors by quantifying water risks and mapping stakeholders for a water stewardship partnership in the basin. Water risks were quantified using indicators from remote sensing platforms and secondary sources. Stakeholder mapping was conducted using stakeholder analysis, while stakeholders' views were collected using questionnaires. The results showed that there is a high fluctuation in the vegetation cover and primary productivity in the basin pointing to a degradation and deforestation. It was also noted that there is an increase in the frequency and severity of drought and high evapotranspiration rates in some parts of the basin due to the low vegetation cover. Combining the results indicated an increase in water risk between 2000 and 2014 in different parts of the basin at a different magnitude of risks. The conducted interviews found that the basin lacked a stewardship program. However, there was a potential for a successful stewardship partnership among stakeholders as most of the stakeholders showed their ability to play a role in the stewardship program. The paper showed a need to form a water stewardship program at the basin to tackle drought, deforestation, and land degradation. The proposed water stewardship program should be built on commitment, transparency, and inclusivity.
\end{abstract}

Keywords Water risk index $\cdot$ Action framework $\cdot$ Degradation $\cdot$ Stakeholders mapping $\cdot$ River Nzoia Basin

\section{Introduction}

\section{Water stewardship partnership}

Stewardship is the willingness to be accountable to a larger group that is operating in a service and working to achieve a fundamental change (Shepheard and Norer 2013). Stewardship is a form of collaborative planning, responsible management of the environment through sustainable natural

Editorial handling: Tajudeen Iwalewa

Kasiti Felix Isundwa

kasitif@yahoo.com

Khaldoon A. Mourad

Khaldoon.Mourad@cme.lu.se

1 Pan African University Institute of Water and Energy Sciences Including Climate Change, 119, Pôle Chetouane,

13000 Tlemcen, Algeria

2 Center for Middle Eastern Studies, Lund University, 201, SE-221 00 Lund, Sweden resources management with respect to the ecosystem function (Mathevet et al. 2018). Water stewardship is viewed as a comprehensive concept that includes the evaluation of the sustainability of water use across the entire value chain (Hoekstra 2017). Water stewardship for business was defined by WWF (2013) as an improved water use and reduced water-related impacts from internal value chain operation while committing to the sustainable management of the shared water resources in the public interest through collective actions with other stakeholders. Companies in water-intensive industries have weak management and disclosure of water-related risks and demonstrate the need for companies to bear the responsibility in their impacts on water resources particularly regarding freshwater scarcity and water governance (Lambooy 2011).

Although there is an increase in environmental stewardship, water stewardship has been taken as a corporate sustainability while stewardship is driven by environmental concerns and is framed within the existing business models of companies (Peter et al. 2015). Since water reduction and quality deterioration will have a great impact on businesses, there is a need for all sectors to be involved in the management of the environment. Locally, there is a need to quantify the various 
risks that are likely to be faced by business and different sectors within the catchment and a need to understand the vulnerability transfer of socio-ecological dynamics.

Motivational barriers to stewardship among users of private wells are limited knowledge on the importance of stewardship while poor education and policy efforts contribute to poor stewardship (Malecki et al. 2017). Stewardship can be in form of reformist, adaptive, sustainability, and transformative (Mathevet et al. 2018). Public engagement is the critical element of stewardship in formal and informal way (Miller et al. 2015). Stewardship evaluation at a catchment level showed that stewardship, in form of restoration, is influenced by the population density, political and program boundary, financial and technical resources, collaboration, and communication (Sheppard et al. 2017). Trust among different stakeholder is the key to the success of a stewardship program by focusing on a single problem at a time (Carrie et al. 2016).

With the wake of climate change uncertainties, the current business models seems unsuitable and pose a threat to the food and beverage industries (Peter et al. 2015) and there is a need for all sectors to work together (Carrie et al. 2016), to link uplands with the aquatic environment, and a need to link stewardship activities to the conservation goals and objectives (Sheppard et al. 2017).

Globally, food and beverage companies such as Britain Food, Coca-Cola, and PepsiCo are addressing water stewardship as a part of their corporate social responsibility (Peter et al. 2015). In Australia, water stewardship formed successfully a stewardship community; with the help of local partners, they formed a stakeholder engagement stewardship that led to a collaborative and supportive partnership (Jones 2017). In the UK, water stewardship for the twenty-first century was advocated to ensure resilience due to the impacts of extreme weather changes (Simpson 2014).

In India, Nestlé, which is the world's largest food and beverage company, has continued to support climate actions and accelerate individual and collective efforts in addressing climate change impacts. They have developed a Natural Resource Stewardship under their Rural Development Framework promoting efficiency, pollution reduction, adaptive climate, and zero wastes among others (Khajuria 2016). In Lusaka, a successful partnership to protect wellfields in an environmentally, socially, and financially sustainable manner securing groundwater supply for Lusaka's residents and businesses were reached and different partners agreed to minute their commitment (Farrington 2016). In Uganda, over 500 ha of wetland areas were restored through a partnership between companies and local industries operating in River Ruwizi Catchment (Parr 2017). In Tanzania, a partnership was formed between development partners aimed at restoration of the Mlalakua River and prevent further pollution from solid and liquid pollution which succeeded (Behnsen 2016). In Kenya, the Government of Kiambu County seeking to address the protection of water and the environment sought support from International Water Stewardship Programme (IWaSP) to facilitate collaboration between private sector and Water Resources Users Association in the county leading to positive feedbacks from companies involved on the potential partnership (Ran 2017). A water stewardship partnership program was launched in Lake Naivasha Basin to improve water availability for domestic and business use within the basin and to improve water quality by implementing soil and water conservation activities (INWaSP 2011).

\section{Water risks assessment}

There are many studies that have defined the risk (SajediHosseini et al. 2018a; Darabi et al. 2019). Risk in general is the chance, high or low, that something could be harmed by hazards, together with an indication of how serious the harm could be (Burt 2001). Water risks are defined as the effect of water-related uncertainty such as pollution, water scarcity, governance, inadequate infrastructure, and extreme events (Orr et al. 2009). Water risks have been categorized into three types: physical, regulatory, and reputational risks. Physical risk is related to water quantity and water quality. Regulatory risk is defined as the risks relates to the imposition of restrictions on water use by government or the regulatory authority such as tariffs and licensing. Reputational risk is defined as how water will impact a company's brand and image and can affect customer purchasing decisions manifested through conflicts and tensions around access to water (Smith et al. 2011).

For the purpose of this study, the risk assessment focused on physical risks that occur regarding water quantity and quality due to human activities. Water scarcity is human driven due to the demand increase or climatic driven as climate change is likely to increase the variability of precipitation and frequency, thus causing water scarcity uncertainty scenarios. Therefore, climate change and human activities have the greatest impact on the ecosystem increasing physical water risk (Stuart et al. 2009; Veldkamp et al. 2016). Physical water risks deteriorating water quality due to eutrophication, human activities, and the over-exploitation of the rivers and the groundwater (EEA 1999).

In South Africa, there has been a tremendous deterioration of water quality in dams over the last 20 years and its attributed to pollution by mining, industry, agriculture, development, and human settlements and the WWF used Water Risk Filter (WRF) to assess the risk to the business. WRF uses risk factors such as aridity, rainfall variability, monthly water depletion, groundwater abstraction drought, regulatory risk indicator, and pollution to derive a global water risk map. This has indicated that various regions of South Africa face high water risk with regions classified as facing water deficits (WWF and KFW 2018). According to Water Security Risk Index, 
Algeria, Egypt, Libya, Tunisia, and Niger are facing extreme water risks. This risk was derived by measuring countries' water stress, population rates, reliance on external water supplies, sustainability of water use, intensity of water use in the economy, government effectiveness, and virtual water use (VM 2018).

Kenya facing water shortage and sediment problems (Gathagu et al. 2017, 2018). The demand for water in the capital city has outstripped the supply by $600 \%$ (SD 2018). However, there are no studies that have quantified water risks locally considering the local and global dynamics. In previous studies, risks had been quantified to address business risks that faced an event of water stress and had combined the use of satellite imagery, climate data, vulnerability assessments, and other economic indicators for spatially map and quantify risks. Analysis has been done by looking at domestic water needs and water supply (Metobwa et al. 2018) where regions with water scarcity or regions facing higher water risks have been mapped basing on these needs. Looking at the various developed water risk indicators, most of them have used indicators such as climate hazards, pollution, population growth aridity, water demand, rainfall variability, groundwater abstraction, and drought. These studies have quantified water risks successfully; however, they have failed to consider the indicators or factors that lead to water risks such as degradation, rainfall use efficiency by drops, vegetation factors, and soil water stress while also have neglected the ecological water requirements. There are indicators that are directly related to water availability and their relationship could point to water risk situation in a water basin. Vegetation indices such as LAI, NDVI, and NVI are used to show land degradation which has a direct relationship with water availability (Choubin et al. 2017; Sajedi-Hosseini et al. 2018b). Climate variability data is an indicator how the changes that are occurring and historical data will point to the variation with time of weather elements such as rainfall and temperature. Soil water information is used to show the water stress that plants could be facing during various times of the year and at different growth stages. The methodologies used in previous studies are complex and are not suitable for policymakers. Therefore, there is a need for a simpler method for risk quantification with the inclusion of factors into the assessment of water risks and develop a water risk index taking into consideration ecological and human water requirements.

Several factors lead to water insecurity in Kenya and are of importance in the assessment of future water risks such as floods, droughts, forest degradation, land degradation, population growth, lack of water supply management, and water contamination among others (Marshall 2011). Deforestation in Kenya is attributed to agricultural mechanization and resettlement which have been magnified due to the institutional failures, lack of consultations, and poor resource decentralization (Atela et al. 2015). Industrial pollution is estimated as the highest source of pollutants as in the case of Athi River Kenya (Munyao et al. 2017). Deforestation, human settlement, and agricultural activities are observed in most catchments in Kenya (Achieng et al. 2017) while the Ministry of Forestry and Wildlife stated that besides climate change factors, population growth, and poor governance as drivers of deforestation and degradation, other factors such as agricultural extension (subject to population pressure, poverty, limited source of alternate income, etc.), excision, logging, livestock grazing, and infrastructure development as drivers of degradation (MoF\&W 2013).

Drought in Kenya has been attributed to ongoing climate change while the severity of the drought impacts $\mathrm{w}$ made worse and may be attributed to a series of events which are human (Kioko 2013). Floods have reportedly increased in the recent times in Nzoia basin (Odira et al. 2010) and both phenomena attributed to land use changes in the basin that has led to land degradation. The increased agricultural lands over the years increased the peak flows in the river during the rainy seasons while reduced the flow during the dry seasons. The area under forest cover has decreased thus affecting runoff and peak stream flow while the area under agriculture and riverine agriculture has increased also having a similar effect on stream flows (Odira et al. 2010).

\section{Stakeholder mapping}

There is a growing need for greater stakeholder engagement in order to assess, manage, and communicate about risks (VanceBorland and Holley 2011). Stakeholders mapping in similar groups builds cohesion and bridges gaps among stakeholders leading to a successful participation (Reed and Curzon 2015). Stakeholder values overlap based on the interest they vest upon a resource necessitating for specific management practice in an area thus mapping of stakeholders informs best management regulations to be implemented (Ruiz-Frau et al. 2011). Stakeholder mapping is a collaborative process of research that draws from multiple perspectives to determine a key list of stakeholders across the entire stakeholder spectrum and involves the steps of identifying, analyzing, mapping, and prioritizing stakeholders based on the group they fall in, perspectives and interests, relationship with other stakeholders and their relevance to the objectives (Olson et al. 2011).

The concerns about water risks have increased due to the increase in water demand, population growth, and the impacts of climate change. Physical risks may occur where there is too little, too much, or polluted water from the various sources. The government and the business sector share the risks related to water scarcity, poor management or the change in water regulation. Therefore, water risk assessment is needed for the government and the businesses sector within a watershed to design a holistic approach in which business, government, and communities can combine their efforts in managing water 
resources to reduce possible future water risks. This study aims at assessing the potential for a water stewardship partnership within Nzoia River Basin (NRB), Kenya (Fig. 1), by (1) quantifying water risks at NRB, (2) mapping the potential partnership stakeholders in the basin, and (3) assessing the potential for stewardship partnership at NRB.

\section{Materials and methods}

\section{Study area}

$\mathrm{NRB}$ lies between longitude $34^{\circ} \mathrm{E}-36^{\circ} \mathrm{E}$ and latitude $00^{\circ} 00^{\prime}$ $\mathrm{N}-1015^{\prime} \mathrm{N}$ with an approximate area of $12,696 \mathrm{~km}^{2}$ and a population exceeds 3.5 million (Fig. 3 ). The basin receives an average annual rainfall of $1350 \mathrm{~mm}$ (Li et al. 2009). The altitude of the basin is between $1070 \mathrm{~m}$ southwest-2700 m northwest with the highest point at $4321 \mathrm{~m}$ which is the peak of Mount Elgon which is also the source of tributaries Ewaso Rongai, Koitobos, Kuywa, and Soisio while Sosiani, Nureni, and Kipkaren originate from Cherangany (Kirugara and Nevejan 1996). The basin is drained with several rivers and streams draining into the main river which flow into Lake Victoria. The length of the longest channel is approximately $355 \mathrm{~km}$ with the mean discharge of $118 \mathrm{~m}^{3} / \mathrm{s}$. However, the flow varies from $20 \mathrm{~m}^{3} / \mathrm{s}$ in extreme drought to $1100 \mathrm{~m}^{3} / \mathrm{s}$ in extreme flood (Joab et al. 2016).

From a physiographic and land use point of view, the basin has four distinct zones: a mountain zone, plateau zone, transition zone, and lowland zone. The mountainous area faces degradation since its covered by forests, and the plateau zone is an agricultural zone majorly (Odira et al. 2010). Forest cover had reduced between the 1970 s and 1980 s by $43.1 \%$ and increased by $41.3 \%$ between 1980 s and 2000 with the decrease attributed to logging, clearing of land for settlement, and agriculture while the increase to government initiative of tree plantation. The major land use types are montane forests, forests, bush/shrub, agriculture, sugar cane, and settlement areas (Dulo et al. 2010).

\section{Water Risk and Action Framework (WRAF)}

The Water Risk and Action Framework was developed in 2013 by the International Water Stewardship Programme (IWaSP) working alongside public bodies, civil societies, and GIZ among other development partners with the aim of identifying and reducing shared water risks. WRAF was developed to help in forming and executing water stewardship partnerships using the cross-sector approach that has five phases to help in increasing the quality of the partnership

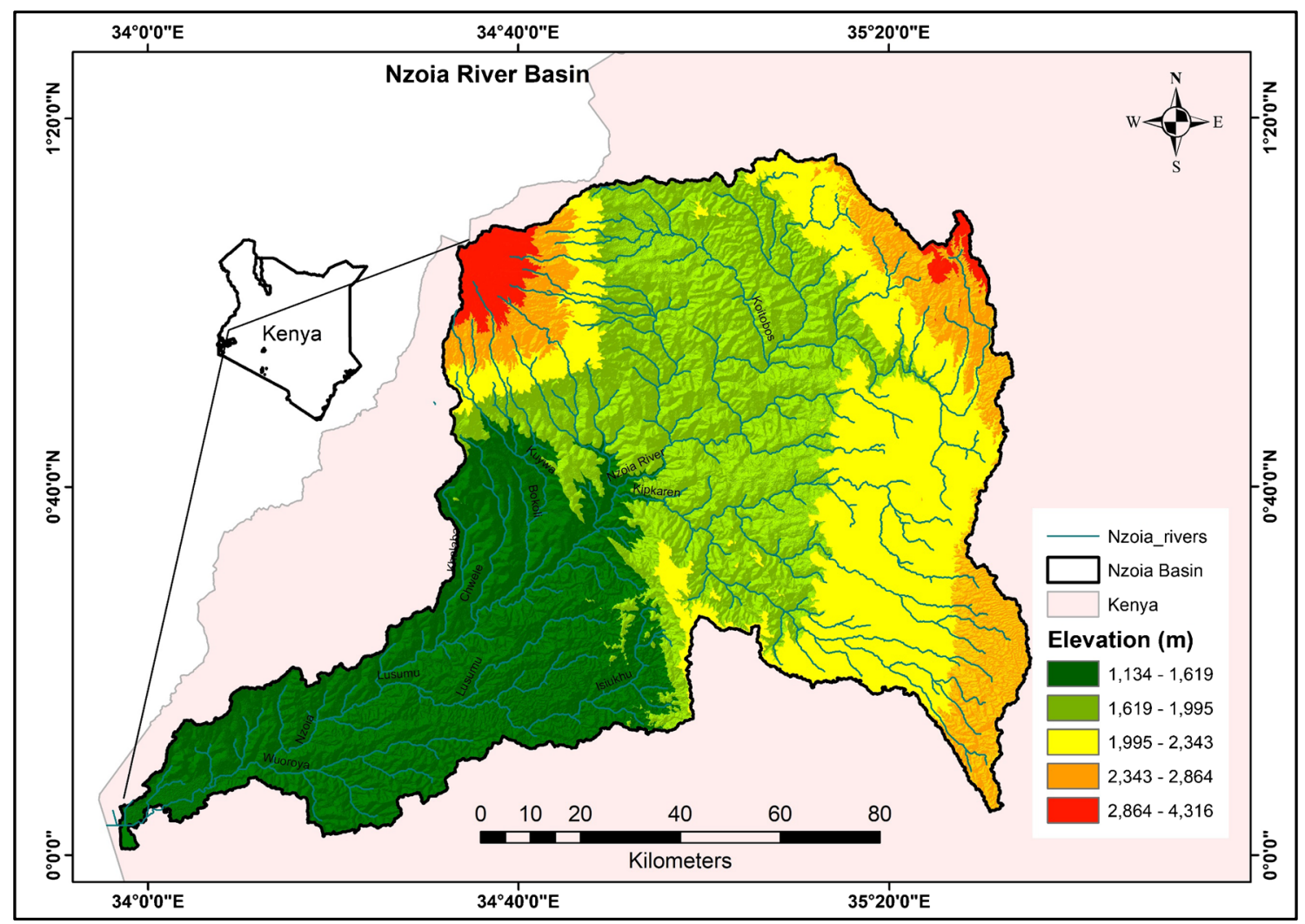

Fig. 1 Study area map Nzoia River Basin (WRA 2018) 
and ultimately achieving water security (IWaSP 2018): (1) prepare phase integrates elements; (2) assess phase which all together involves; identify stakeholders and markets, share problems and recognize interests, prepare roadmap, assess risks and opportunities, determine costs and benefits, shape partnership; (3) commit phases involves developing business cases, developing a mode of delivery, and securing the commitment of actors; (4) the act phase consists of empower and advise actors, coordinate, and manage implementation and monitor progress; and (5) scale and exit phase involves the evaluation of impact and lessons, leverage impact at scale, and phasing out. There are tools designed for use in several theme areas such as risk assessment and water risks mitigation among others (IWaSP 2018).

For the purpose of this study, themes from the prepare and assess phases were used to assess the potential for a water stewardship partnership. The study begins with an assessment of water-related risks in the catchment followed by mapping of the potential stakeholders' partnership.

\section{Quantifying water risks}

In this study, indices were assessed to quantify water risks in the catchment by aggregating the various indices: leaf area index (LAI), the Priestley-Taylor alpha coefficient, rainfall use efficiency, soil water stress, slope, and Climate Hazards Group InfraRed Precipitation with Station data (CHIRPS) was aggregated into a single water risk index.

\section{Leaf area index}

The energy, water, and carbon exchanges between the land and atmosphere are highly dependent on photosynthesis and is a function of plant leaves. This is largely controlled by the stomata as it is the bridge between highly water-saturated tissues in the leaves and the atmosphere in the exchange of mass used in energy and sugar synthesis using carbon and other nutrients (Sellers et al. 1997). An adequate amount of information on the inclusion of leaf functioning for climate simulation models requires quantitative information about the vegetation (Dickinson 1995). LAI is defined as the projected area of a leaf over a unit of land in $\left(\mathrm{M}^{2} \mathrm{M}^{2}\right)$ and sometimes it is expressed as the basis of all leaf surface area., LAI in need leaf vegetation is defined as the projected need leaf area per unit ground area (Choubin et al. 2017).

$L=N_{\mathrm{p}} \times N_{1} \times A_{1}$

where $N_{\mathrm{p}}$ is the number of plants per unit area; $N_{1}$ is the number of leaves per plant; and $A_{1}$ is the mean area of the leaf in $\mathrm{m}^{2}$.

The number of plants occurring in a location is determined by the percentage of the establishment and the number of seeds sown, influenced by temperature, soil moisture, management practices soil aggregate, size of leaf, and leaf expansion which depends on temperature and nitrogen. LAI can be used to estimate soil moisture supply climate, etc. LAI gives quantitative values as opposed to normalized difference vegetation index (NDVI), which gives qualitative values on how lush the vegetation is. Determination of LAI over land is a key in determining the energy balance over the land surface. LAI is used in quantifying carbon fluxes in the atmosphere (Dickinson 1984).

Optical remote sensing is a valuable tool to assess the changes in biomes (an area of the planet that are classified according to the plants and animals that live in it) and other ecosystem characteristics in response to climatic changes over a huge area and with multiple and long time periods (Huemmrich et al. 2010). Remote sensing methods generate dimensionless LAI values assigned per pixel and can range from 0 to 6 or more, LAI for rangeland which has sparse vegetation, values range from 0 to 1.1 indicates the vegetation covering the entire unit surface area of the ground and values less than 1 means there is bare ground between vegetation patches.

Buermann et al. (2002) simulated LAI by observing how light is reflected using near infrared and visible light. The empirical relationship that is there between LAI and spectral vegetation indices such as NIR, red band ration, and NDVI suggests that the radiative transfer method of assessing LAI is the best since NDVI is sensor specific. The field observation data that is used to validate the satellite LAI shows there is a relationship and the values are comparable according to the selected sites of study (Myneni et al. 1996). LAI values are related to climatic data and there is a direct relationship between LAI and the ENSO cycle where the anomalies in the sea surface temperatures have affected the values of LAI. It was also observed that the warm temperatures promote growth (Dai et al. 1997).

The use of LAI in quantifying the biomes change in a region over a period of time is advantageous over the use of NDVI as it gives the quantitative value to LAI as opposed to the NDVI. This can be used in quantifying the likelihood of degradation or a catchment by looking at the changes of LAI over time. It can also be used to give information about the variation of temperature rainfall, ENSO, and climate data which are all important factors in growth.

For global or large-scale estimation of LAI over the land surface and for a time series, remote sensing is a powerful tool that collects data from sensors mounted on satellites orbiting the earth. Moderate resolution image spectroradiometer (MODIS) is one of the sensors aboard Terra and Aqua satellites which has been in orbit since 2000 and has been providing a source of LAI data with calibration and fusing from other sensors to give long-term LAI series. MODIS is aboard the space crafts is viewing and acquiring data at 36 spectral bands. 
There is an indirect relationship between LAI and land degradation where an increase in LAI means less degradation as opposed to the low LAI values that point to degradation. Degradation is an indicator of water risk in a catchment as the decrease in cover crop leads to an increase in evaporation and evapotranspiration rates on land. Therefor water risk (WR) can be expressed by the following equation:

$\mathrm{WR}=1 / \mathrm{LAI}$

\section{The Priestley-Taylor alpha coefficient}

The water availability in soils, soil moisture, is an important factor for plants growth. The lack of adequate soil moisture in an area leads to crop failure and hinders reforestation efforts. Areas that have high air temperature and high soil temperature experience water stress due to high evapotranspiration $\left(\mathrm{ET}_{0}\right)$. A study of the surface energy budget is used to estimate evapotranspiration. The Penman equation (Penman 1948) developed one of the methods used to estimate evapotranspiration.

Priestley and Taylor (1972) in the calculation of daily $\mathrm{ET}_{0}$ ( $\mathrm{mm} /$ day) replaced the aerodynamic term of the PenmanMonteith equation by a dimensionless empirical multiplier (a, Priestley-Taylor coefficient):

$\mathrm{ET}_{0}=\frac{s \times(R n-G)}{S+\gamma} \times a$

where

$\mathrm{ET}_{0} \quad$ potential evapotranspiration

$\mathrm{Rn}$ the net radiation $\left(\mathrm{MJ} / \mathrm{m}^{2}\right.$ day)

$G \quad$ the soil heat flux $\left(\mathrm{MJ} / \mathrm{m}^{2}\right.$ day)

$s \quad$ the slope of the saturation vapor pressure-temperature relationship $\left(\mathrm{kPa} /{ }^{\circ} \mathrm{C}\right)$

$\gamma \quad$ the psychrometric constant $\left(\mathrm{kPa} /{ }^{\circ} \mathrm{C}\right)$

$a$ the Priestley-Taylor coefficient

The Priestley-Taylor equation is applicable for the calculation of daily $\mathrm{ET}_{0}$ for conditions where there is a limited data such as weather inputs for the aerodynamic term (relative humidity, wind speed). On land, the latent heat of evaporation is affected by the radiation that is received on the surface, $\alpha$ is very useful in the analysis in unsaturated surface, and Priestley observed that unsaturated surface had lower values than saturated surfaces and the ratios of low alphas is regarded as aridity index (Priestley and Taylor 1972).

Priestley et al. (1972) developed a streamline to solve (Penman 1948) parameterization problem leaving the formulation of radiation and temperature-based equilibrium evaporation. However, this method estimated only the potential evapotranspiration (PET) not the actual evapotranspiration (AET). Fisher et al. (2008) introduced a unitless function into the Priestley-Taylor equation for remote sensing studies that are used to derive the AET. The PT-FI model is based on the atmospheric moisture and vegetation indices (NDVI) and soiladjusted vegetative indices (SAVI).

The Priestley-Taylor alpha coefficient (PAC) is generalized as the ratio (dimensionless) of annual AET over the annual PET and as the alpha coefficient approaches 1, and vegetation is uninfluenced by water stress and is used to describe the overall aridity stress on vegetation by integrating monthly soil water availability for vegetation. The higher the coefficient, the lower the water risk while a decrease in the coefficient shows higher water risks. Therefore, WR is:

$\mathrm{WR}=1 / \mathrm{PAC}$

\section{Rain use efficiency}

Desertification is caused due to climatic conditions or human activities and negatively affects land productivity and reduces the plant/perennial cover, which are indicators of land degradation (Kundu et al. 2017). Rain use efficiency (RUE) is defined as the aboveground net primary production (ANPP) divided by rainfall and is used as an indicator of degradation (Dardel et al. 2014). Changes in rainfall distribution or pattern affect vegetation structures, LAI (primary precipitation use index, PUE, driving factor) and thus a possible effect on water and carbon cycles while precipitation is the standard cause of ANPP.

The increase in mean annual precipitation increases ANPP and RUE (Bai et al. 2008). Globally, remote sensing data such as MODIS has been used to develop RUE through different methods such as the novel method (Du et al. 2018), correlation analysis (Zhao et al. 2018), and meta-analysis and regression (Ruppert et al. 2012). RUE has shown a positive correlation with evapotranspiration, while both RUE and vegetation index (VI) are indicators of ecological multifunctionality indicators, RUE is preferred over VI due to the robustness of rainfall (Zhao et al. 2018) and shows a dynamic integration of NDVI and rainfall (Kundu et al. 2017). Although RUE varies in different biomes (Ruppert et al. 2012) and the need for further understanding of climatic and soil factor on growth (Sun and Du 2017), the use of RUE can be used as an ecosystem indicator to show degradation.

\section{Climate Hazards Group InfraRed Precipitation with Station data}

Studying floods and droughts requires accurate rainfall data over a period of time, and satellites offer an alternative to access rainfall data in regions with sparse rain gauges and in inaccessible regions (Toté et al. 2015). CHIRPS is a 30 plus years quasi-global rainfall dataset from 1981 to the 
near present with a $0.05^{\circ}$ resolution with in situ data for trend and drought monitoring (CHG 2018). CHIRPS is built on previous approaches on smart interpolation and high-resolution long period of precipitation estimates based on infrared Cold Cloud Duration observations and several algorithms developed for daily monthly data etc. (Funk et al. 2015a). Satellites perform better in data sparse regions with complex terrain and offer high-resolution data (Funk et al. 2015b). CHIRPS performs better as compared to other data types, although it overestimates rainfall events frequency (Toté et al. 2015) up to $31 \%$ at decadal scale but are better at skills in determination of rainfall event, volumetric rainfall estimation and better bias values (Ayehu et al. 2018). This data is vital to study drought and floods as most countries are experiencing population growth thus the need for food security to suffice the population.

The Africa Soil Information Service (AfSIS) derived RUE using MOD17A3H NPP (net primary production) and CHIRPS (Climate Hazards Group InfraRed Precipitation with Station) with results in $\mathrm{g} / \mathrm{Cm}^{2} \mathrm{~mm}$, and $\mathrm{tC} / \mathrm{ha} \mathrm{mm}$ (AfSIS 2015) and has been suggested as a measure of land degradation. RUE is given as the annual sum NPP/ annual sum CHIRPS and is given as using $\mathrm{tC} / \mathrm{ha} \mathrm{mm}$ : the amount of biomass produced (tons of carbon mass per hectare) per millimeter of rainfall. The higher the RUE value, the lower the water risks in the catchment, thus giving the inverse proportional relation of RUE to WR.

$\mathrm{WRI}=1 / \mathrm{RUE}$

\section{Soil water stress}

Water is an essential molecule in the plant biomass since it is essential for physiological processes and water stress occurs when the supply of water to the roots become limiting (Lisar et al. 2012). The state of water in soil is expressed in terms of the amount of water and the energy associated with the forces holding water in the soils while the amount of water is described by the content and the energy state which influence the plant growth, soil temperature, chemical transport, and groundwater recharge (Bilskie and Scientific 2001). Drought is the most limiting factor for field crops in arid and semi-arid regions with the varying degree of drought stress affecting the amount of dry matter produced and the quality of seeds produced by crops (Gholamhoseini et al. 2013). The percentage of the maximum soil water content that is available for evapotranspiration is equal to the soil water stress coefficient and is a measure of the soil stress expressed monthly. These values expressed monthly ranging from 0 to 100 with higher values indicating high potential of evapotranspiration and thus a lower water risk.
$\mathrm{WR}=1 / \mathrm{SWS}$

\section{Water risk index (WRI)}

The LAI, the Priestley-Taylor alpha coefficient, rainfall use efficiency, and soil water stress are indicators of the water risk in the basin and aggregation of these risk indicators give a WRI of the basin. WRI was derived by combining the different indicators, using Eqs. 2, 4, 5, and 6 . Aggregation of these indicators into one will give a water risk index that will show the spatial-temporal variation of risk factors within the basin ( Eq. 7).

$\mathrm{WRI}=\frac{1}{\mathrm{LAI} \times \mathrm{RUE} \times \mathrm{SWS} \times \mathrm{PAC}}$

\section{Data acquisition}

\section{Data collection on stakeholders}

Purposive sampling technique (Tongco 2007) with a target sampling population of 50 respondents was used. Semistructure questionnaires were used to collect stakeholders' views and the informants were selected based on their geographic locations, interactions, and interest in water resources within the study area. Stakeholders were assigned categories based on the type of organization they represented. Stakeholder mapping is guided by stakeholder analysis template developed by IWaSP (2018) and the stakeholder responses on their willingness to partner was analyzed using the Microsoft Excel and represented in form of charts, tables, and graphs by applying descriptive statistics on the collected responses.

\section{Data analysis and assessment}

LAI and RUE data were obtained from AfSIS (2015) with spatial resolution on $1000 \mathrm{~m}$ in a GeoTIFF format for Africa continent. SWS and PAC data was acquired from Trabucco and Zomer (2010) with a resolution of 30 arc sec in ESRI grid format for global data. SWS and PAC raw data were downloaded from the NASA (2014) and batch scripts were used to automate the interaction with the MODIS reprojection and GRASS GIS, in a LINUX environment, to geoprocess and mosaic all the tiles relevant for Africa (GitHub 2010) with a resolution of $1000 \mathrm{~m}$. SWS and PAC data is in global format while LAI and RUE were for Africa continent. PAC data was obtained from the Consortium for Spatial Information (CGIAR-CSI) (Trabucco and Zomer 2010) with a resolution of $30 \mathrm{arcsec}(\sim 920 \mathrm{~m}$ at the equator). The data clipped in ArcGIS 10.2 using the spatial analyst tool with RNB as the mask as the processing extend. 


\section{Data analysis tools}

The ArcGIS program was used to analyze the data using the raster calculator to derive the water WRI. The resulting output is a unitless raster value with values between 0 and 0.05 . The raster is assigned classes with the various risk levels (Table 1).

\section{Results and discussion}

\section{Quantifying water risk}

Water risk in the basin was determined by a combination of four indicators that include the LAI, RUE, Priestley-Taylor alpha coefficient, and SWS.

\section{Leaf area index}

The LAI data (Fig. 2) is a representation of the standard deviation values with a temporal range between February 2000 and December 2016. The data shows a major portion of the basin has had low variation in the LAI value since 2000 with a sizable area of the basin having high values of LAI variation. The northwest and northeastern parts of the basin which is high altitude areas and considered as the water towers of the basin seem to be most affected in the LAI values variation. LAI is affected by natural factors (interaction between vegetative and reproductive components, climate) and human factors (pruning of trees, farming, deforestation), while it has been observed that LAI affects partitioning between green water (evapotranspiration) and blue water (infiltration, aquifer recharge, stream flow) making it an important indicator of the ecosystem function and status (Taugourdeau et al. 2014). From the data below, it is evident that there is deforestation along the slopes of Mount Elgon and along the Cherangany ranges which fall along the northwest and northeast of the basin. There is evidence of degradation along these areas too due to the variation of LAI with the central part of the basin experiencing high LAI variation. MODIS15LAISLT is an AfSIS code for the MOD15A2H level 4 version 6 for MODIS product that combines LAI and combined fraction of photosynthetically active radiation (FPAR) which is an 8day composite data set with 1000-m resolution.

Table 1 Risk analysis classification

\begin{tabular}{lll}
\hline Classes & Assigned class & Risk category \\
\hline 0 to 0.01 & 1 & No risk \\
0.01 to 0.015 & 2 & Low risk \\
0.015 to 0.020 & 3 & Medium risk \\
0.020 to 0.025 & 4 & High risk \\
Over 0.0250 & 5 & Very high risk \\
\hline
\end{tabular}

\section{Priestley-Taylor alpha coefficient}

The PAC is generalized as the percentage of annual AET over an annual PET. As the alpha coefficient approached $100 \%$, vegetation was uninfluenced by water stress. This effectively indicated the effects of aridity stress on vegetation since it integrates monthly soil water availability for vegetation requirements through a generalized soil water balance (Trabucco and Zomer 2010).

From the data analyzed (Fig. 3) between 2000 to 2014, in about a third of the basin, there is a 46-60\% chance that the vegetation in those areas are affected by water stress while the rest of the basin is less likely to be affected by water stress. This is an indicator that a third of the river basin is likely to experience higher evapotranspiration rates with low water content in the soil. From the results, there is the likelihood of an increased degradation and increased weather variation in the basin that leads to high evapotranspiration rates.

\section{Rainfall use efficiency}

RUE is expressed as the amount of biomass produced (tons of carbon mass per hectare) per $\mathrm{mm}$ of rainfall. The comparison of RUE between 2000, 2010, and 2014 (Fig. 4) shows an increase in the areas with low RUE values with the year 2000 having the smallest area with low RUE values between 0 to $0.011 \mathrm{tC} / \mathrm{ha} \mathrm{mm}$ while the basin recorded higher RUE values of between 0.022 and $0.0279 \mathrm{tC} /$ ha $\mathrm{mm}$. In 2010, the area with the lowest RUE efficiency of between 0 and $0.005 \mathrm{tC} /$ ha $\mathrm{mm}$ significantly increased while the highest recorded values of RUE were between 0.011 and $0.016 \mathrm{tC} / \mathrm{ha} \mathrm{mm}$. In the year $2014,70 \%$ of the basin recorded RUE values of between 0.002 and $0.011 \mathrm{tC} / \mathrm{ha} \mathrm{mm}$ with the highest values between 0.016 and $0.022 \mathrm{tC} / \mathrm{ha} \mathrm{mm}$ being recorded. From the map in Fig. 4, it is evident that there has been an increase in the areas with lower RUE values between 2000 and 2014 while there has been a decrease in the areas with higher RUE values with the highest values decreasing from 0.0279 to $0.016 \mathrm{tC} /$ ha $\mathrm{mm}$ in 2010 with 2014 recording $0.022 \mathrm{tC} / \mathrm{ha} \mathrm{mm}$.

It is evident that there is a decline in the primary productivity of in the basin over the years and an increase in losses of rainfall through runoff and evapotranspiration. These indicate a degrading catchment in terms of soil, and vegetation with a land use changes for settlement and infrastructure development occurring in the catchment.

\section{Soil water stress}

SWS indicates the monthly fraction of soil water content available for evapotranspiration process expressed as a percentage (percentage of maximum soil water content) 


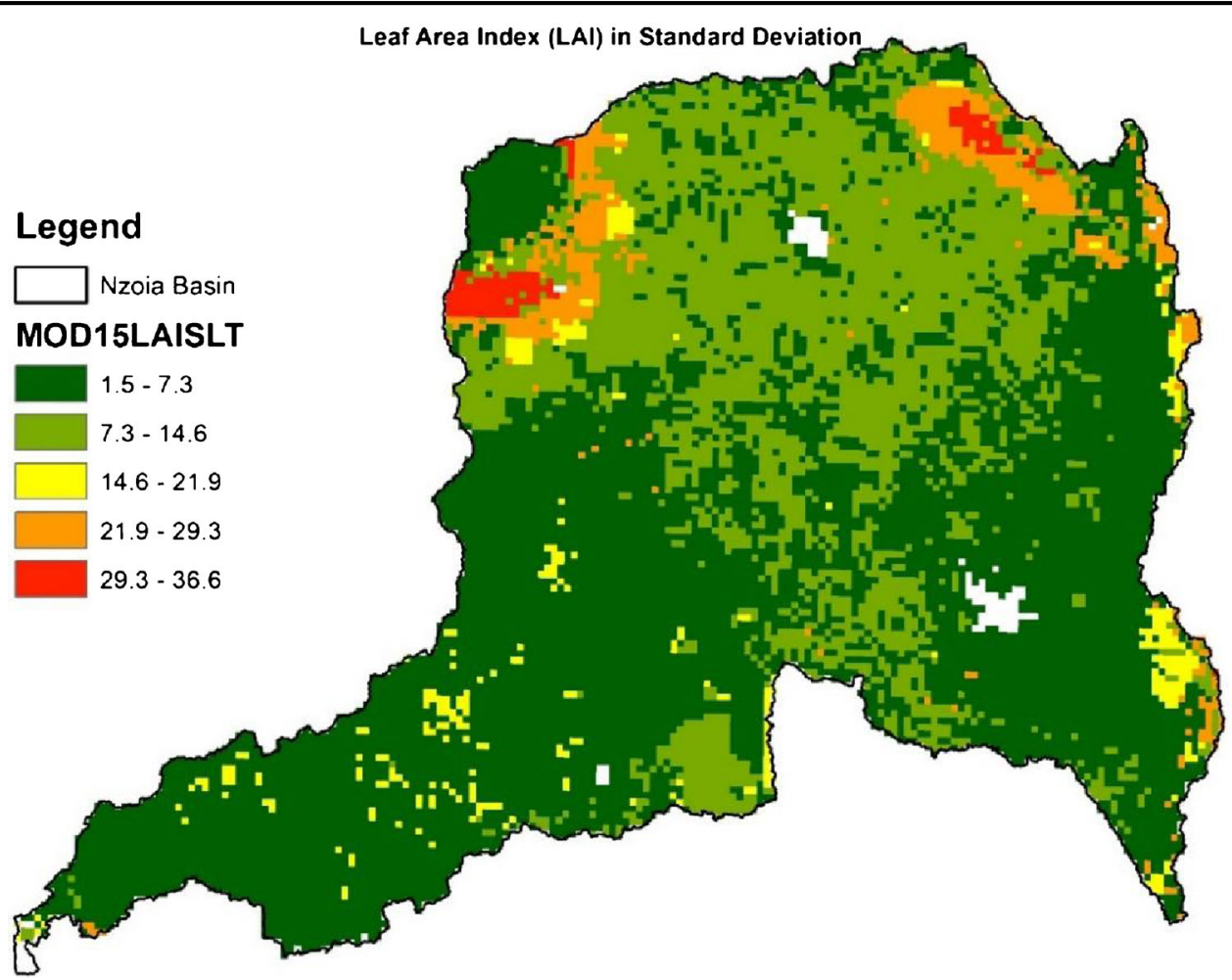

Fig. 2 MODIS MOD15A2 leaf area index (temporal range: Feb 2000-Dec 2016) (data was downloaded from http://africasoils.net/services/data/remotesensing/land/; http://www.geos-ic.com/project/bassin-de-loued-mejerda-protection-contre-inondations-zone-d2-tunisie/)

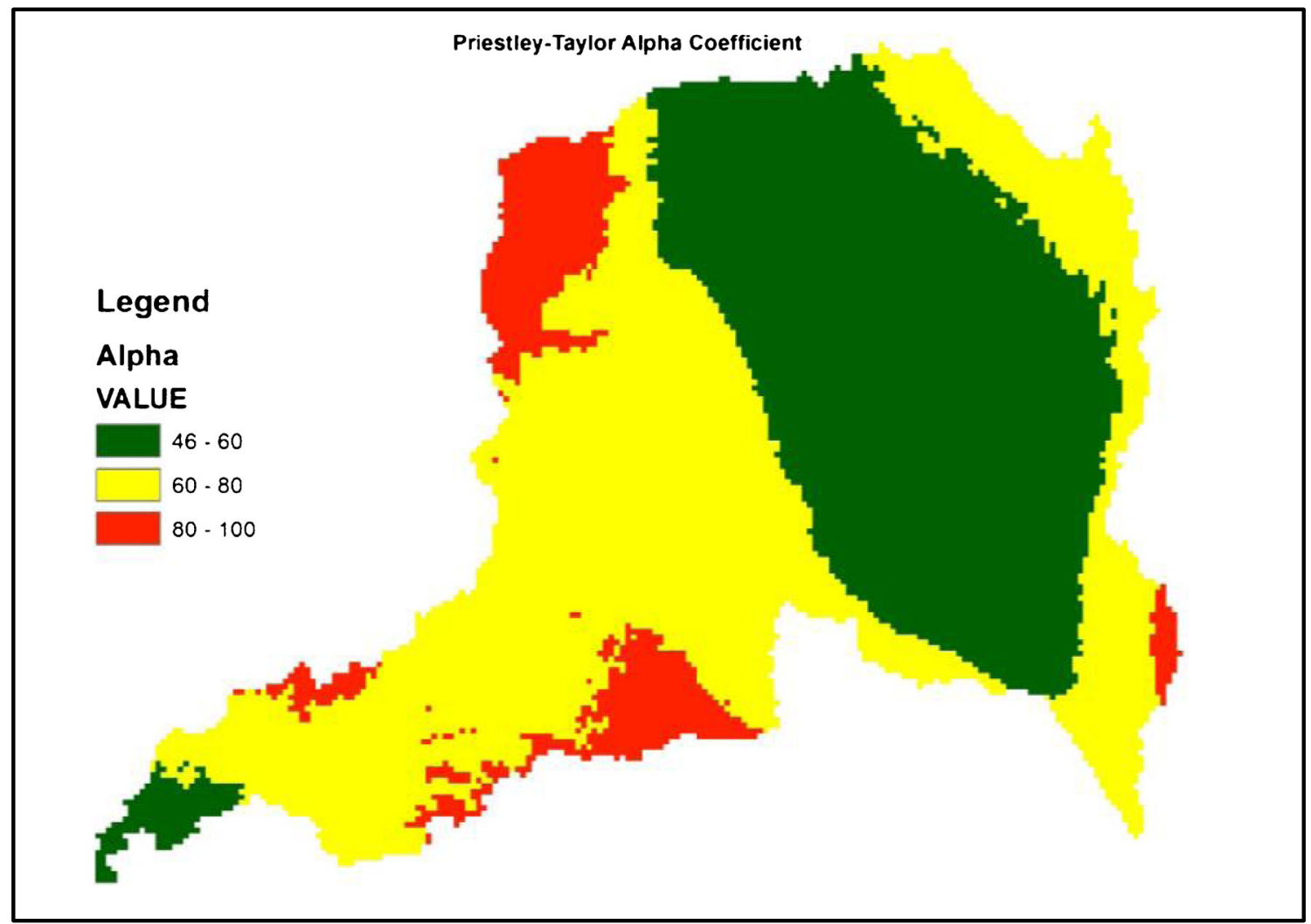

Fig. 3 The Priestley-Taylor alpha coefficient from 1950 to 2000 (this data was acquired from CGIAR-CSI website, https://cgiarcsi.community/data/ global-high-resolution-soil-water-balance/) 
Fig. 4 Rainfall Use Efficiency for 2000, 2010, and 2014 (data was acquired from http://africasoils. net/services/data/remote-sensing/ land/)

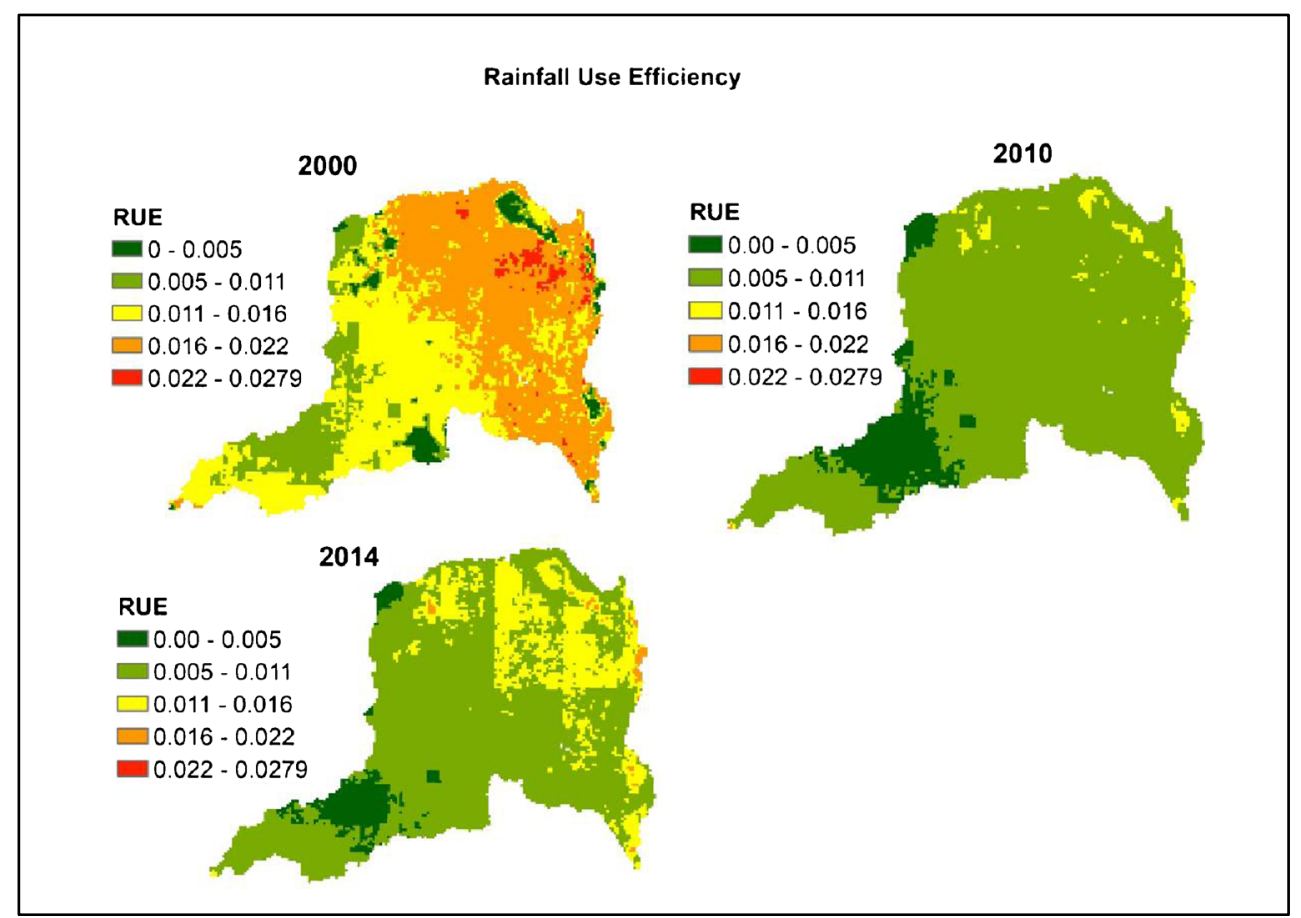

(Trabucco and Zomer 2010). Based on the data from CHG (2018), Figs. 5, 6, and 7 show that the comparison of monthly SWS data-January, February, March, and April-have the lowest percentage with values below $40 \%$ of water available for evapotranspiration thus higher stress levels in the soil. About $40 \%$ of the catchment area experience low soil water capacity in these months. The rest of the basin recorded a fairly high amount of soil water content in the subsequent month with the majority of the basin recording values of above $40 \%$ while a significant area recording values of up between 80 and $100 \%$ indicating very low water stress. The water stress increases with the decrease in the amount of soil water content thus the months of January, February, and March experience higher soil water stress in the majority of the basin. This an indication of increased drought during the first three months of the year in the basin.

\section{Water risk index}

The WRI is calculated by combining the four indicators of risk that are LAI, RUE, SWS, and PAC. The WRI was calculated for the year 2000, 2010, and 2014 on a monthly basis from January to December. The water risks have been categorized into 5 classes from 1 to 5 with 5 and 4 being high risk, 3 being medium risk, 2 being low risk, and 1 no/ negligible risk. Areas falling between 4 and 5 have faced water stress for both human and ecosystem use.
Based on AfSIS (2015), CHG (2018), and GitHub (2010), the analysis for the year 2000 (Figs. 8, 9, and 10) showed that a major area of the basin faced no water risk throughout the year. January, February, March, and April faced low water risk in areas less than $15 \%$ of the entire basin while the rest of the year experienced low water stress. There was no water risk or water stress in the catchment in the year 2000 .

In 2010, analyzing water risks data from AfSIS (2015), CHG (2018), and GitHub (2010), Figs. 11, 12, and 13 show that there was a significant decrease in areas with no water risk while there is an increase in the areas that faced low, medium, and high water risks. The most affected months are January, February, and March where the $30 \%$ of the basin faced medium to high water risks with the affected areas being towards the peak of Mt. Elgon, the central part and the southwestern portion downstream the river. These months are associated with low precipitation due to the migratory nature of the intertropical convergence zone which brings seasonality of rainfall in the region. The rest of the year, a major portion of the basin experience low to no water risk with the exception of the area around the peak of Mt. Elgon (to the northwest of the basin) and the southwest towards the mouth of the Nzoia River, which experienced medium to high water stress throughout the year.

In 2014, according to AfSIS (2015), CHG (2018), and GitHub (2010), Figs. 14, 15, and 16 show that there was a slight decline in the areas that faced medium to high water 
Fig. 5 Monthly soil water stress for the basin (data was acquired from https://cgiarcsi.community/ data/global-high-resolution-soilwater-balance/) risk as compared to 2010 but the areas were large as compared to the year 2000 where the majority of the basin did not record any water risk. The first 3 months of the year are the most affected with a third of the basin facing medium to high risks and notably the downstream/ southwest part of the basin facing constant high risk throughout the year.

\section{Partnership stakeholders}

\section{Stakeholder categories}

Stakeholder partnership was identified based on their roles, interest, and their overall interaction with water resources (Table 2). The stakeholders were categorized into classes that
Fig. 6 Monthly soil water stress for the basin from May to August (data was acquired from https:// cgiarcsi.community/data/globalhigh-resolution-soil-waterbalance/)

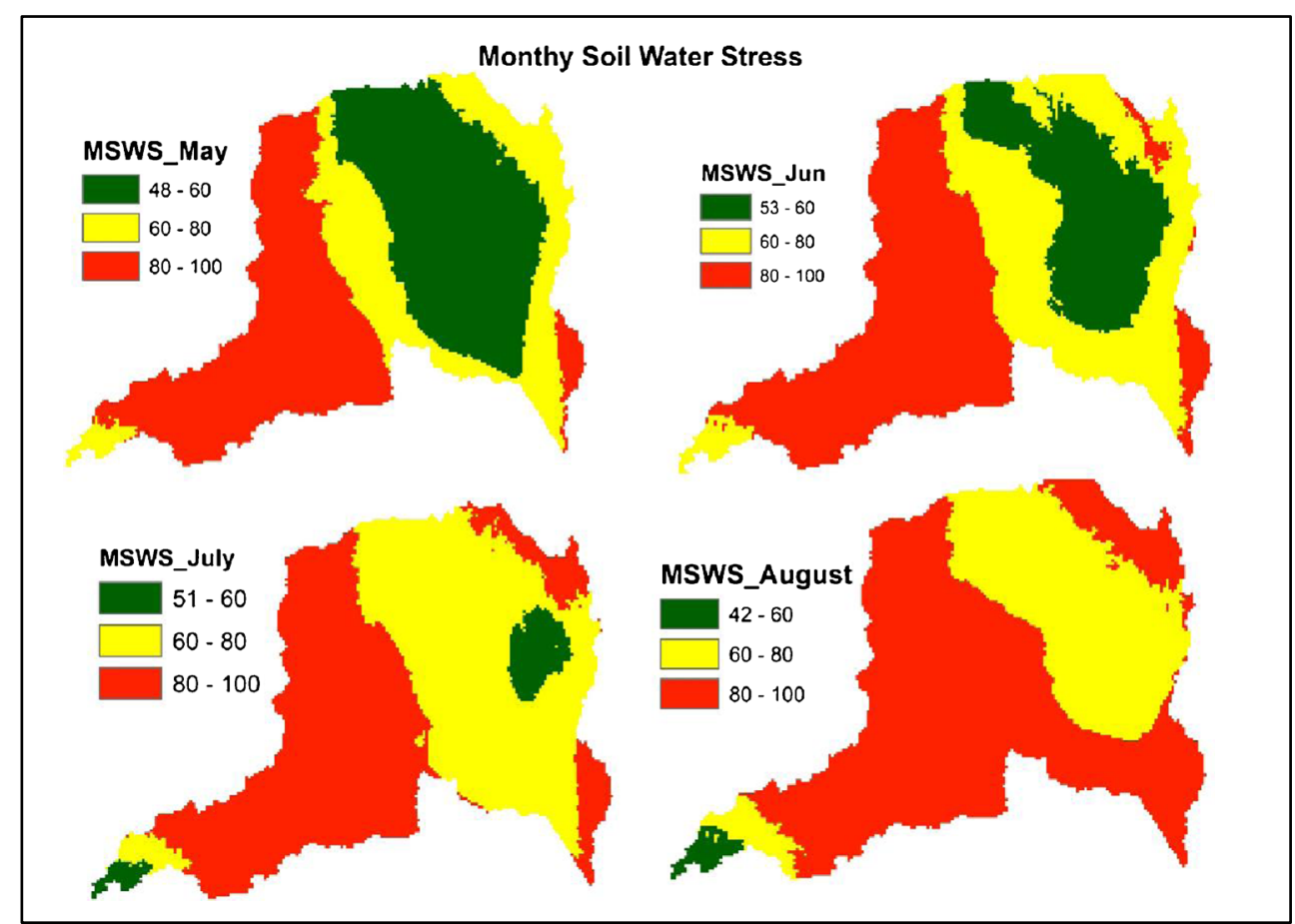


Fig. 7 Monthly soil water stress for the basin from September to December (data was acquired from https://cgiarcsi.community/ data/global-high-resolution-soilwater-balance/)

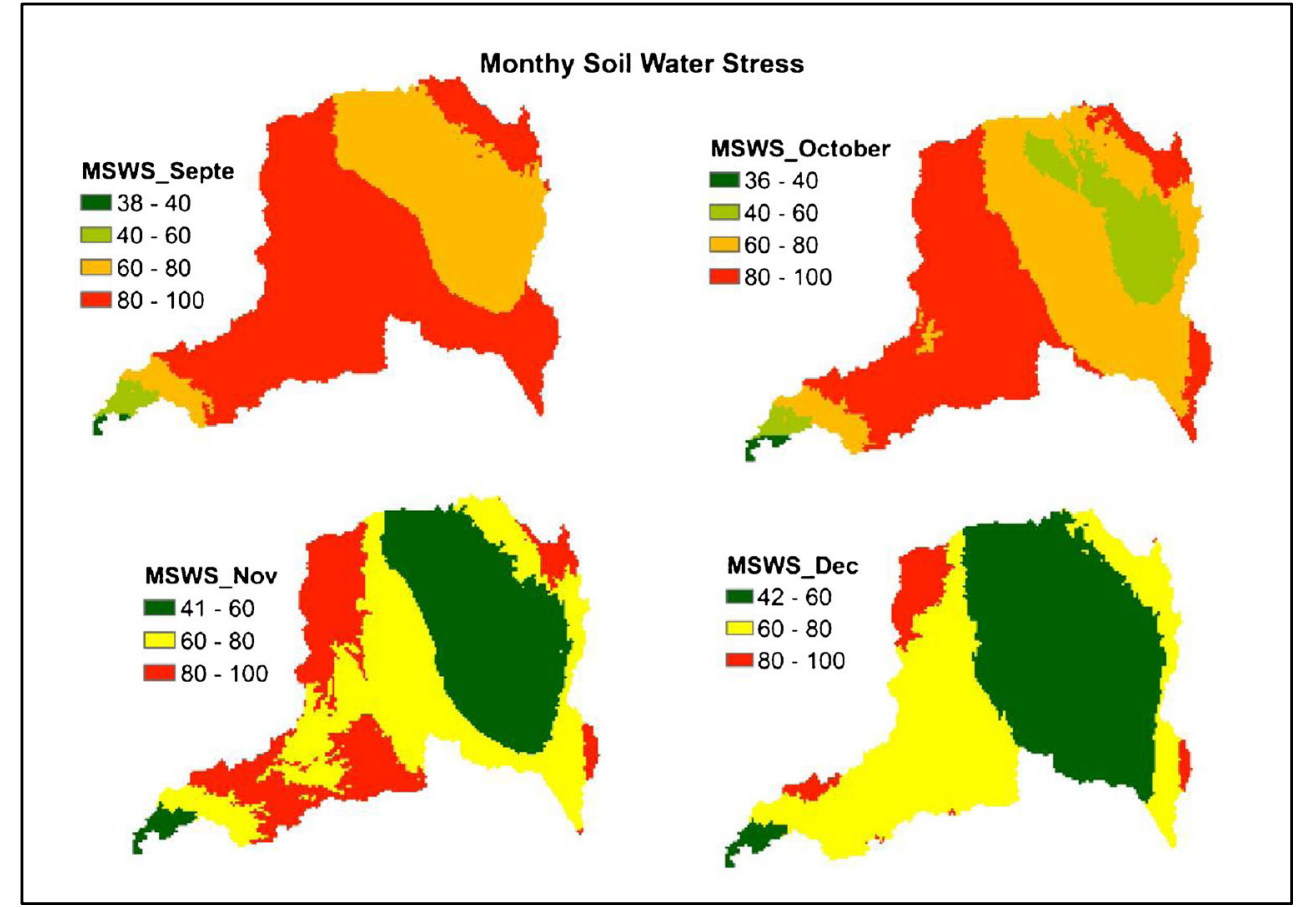

include government authorities, local business, international organization, local NGO, private sector, companies, academia, local community, water user, parastatal, and other using the stakeholder analysis template for IWaSP (2018).

A total of 52 stakeholders were identified as a key in the formation of water stewardship partnership and were identified based on their interest and association to water resources. Seven governmental authorities were identified with an interest in water resources and they include the county government, the ministries of water and environment, and government bodies that have interest in conservation and resource management. Two international organizations were identified as they are interested in water resources management including GIZ. Parastatals in that are involved in water and environmental activities were identified with 9 of them mapped within the basin. The private sector, farmers, and water users were
Fig. 8 Water risk index for the catchment between January and April for the year 2000 (data was acquired from https://cgiarcsi. community/data/global-highresolution-soil-water-balance/)

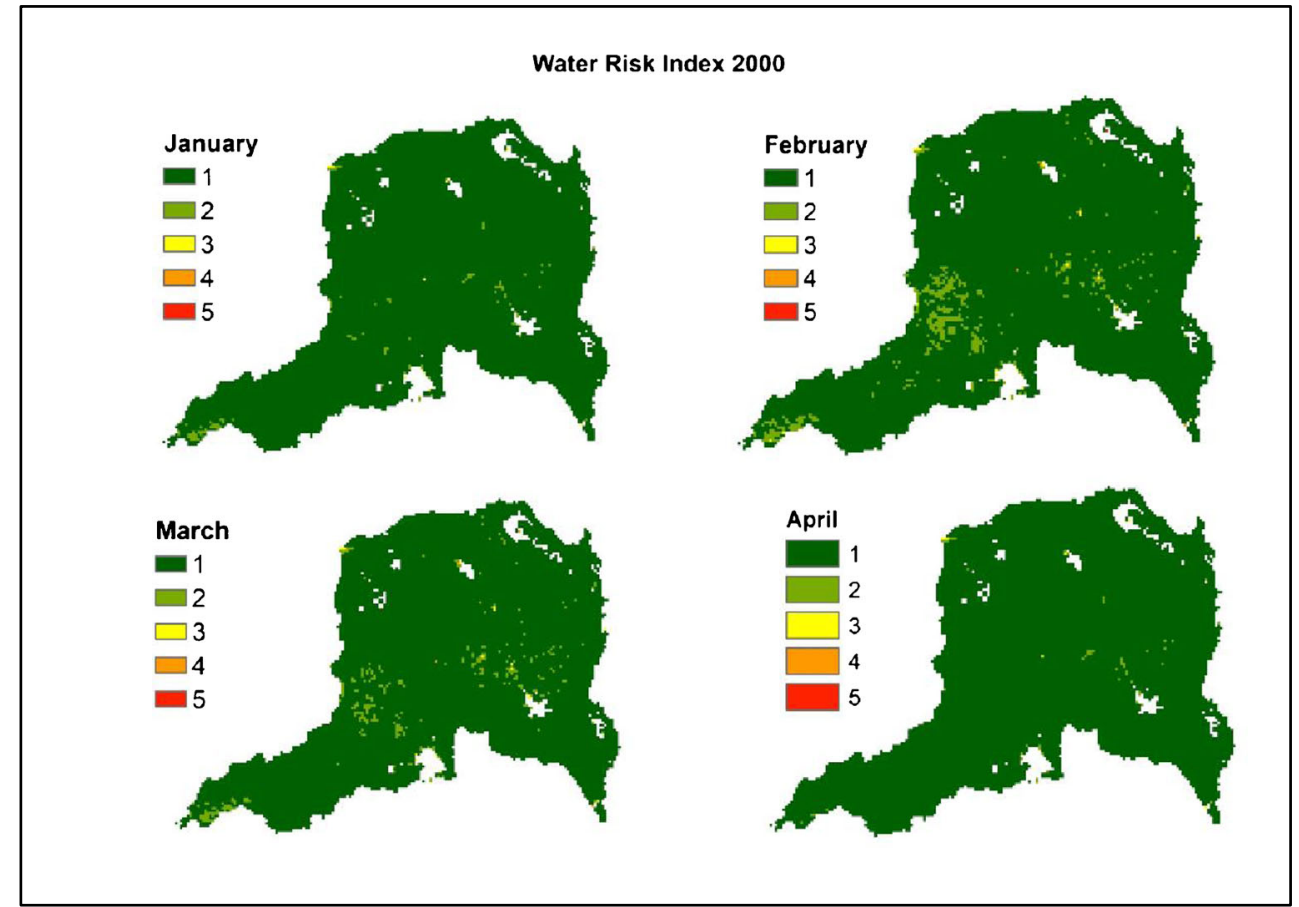


Fig. 9 Water risk index for the catchment between May and August for the year 2000 (data was acquired from https:// cgiarcsi.community/data/globalhigh-resolution-soil-waterbalance/)

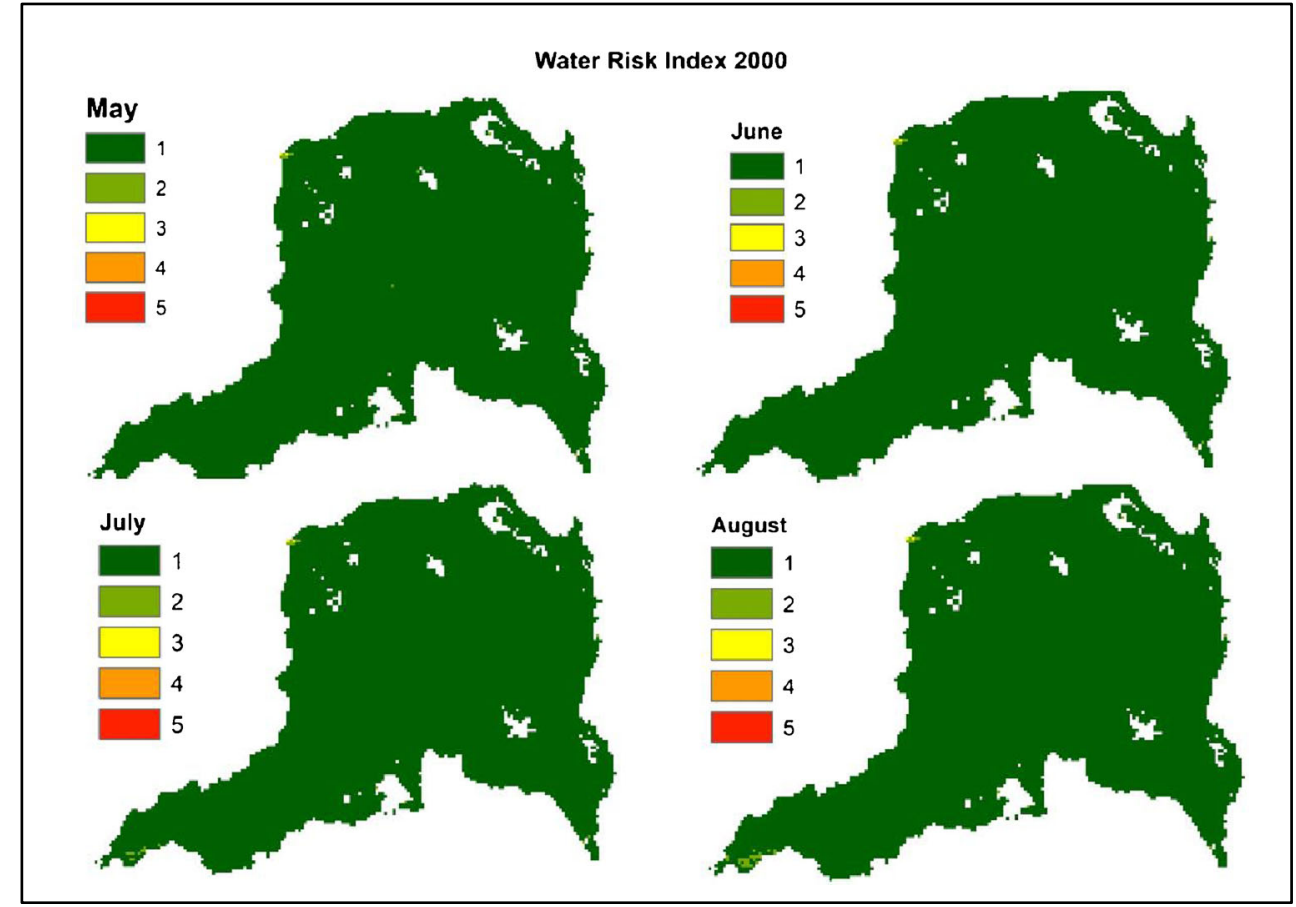

identified while academic institutions with interest to water in the basin were mapped.

\section{Stakeholder group}

Stakeholders for the partnership were categorized into groups basing on their impact and the roles they are likely to play in the partnership. The three categories include core partners (31\%), non-core partners (33\%), and target group (36\%). Core partners are critical to the success of the partnership, and non-core partners will influence the success of the partnership but are not critical, while the target group will influence the project and targeted for implementation of activities proposed. Thirty-six percent of the stakeholders are targeted for the success of the project, $31 \%$ are core partners of the partnership, and $33 \%$ are non-core partners but influence the success of the partnership.
Fig. 10 Water risk index for the catchment between September to December for the year 2000 (data was acquired from https:// cgiarcsi.community/data/globalhigh-resolution-soil-waterbalance/)

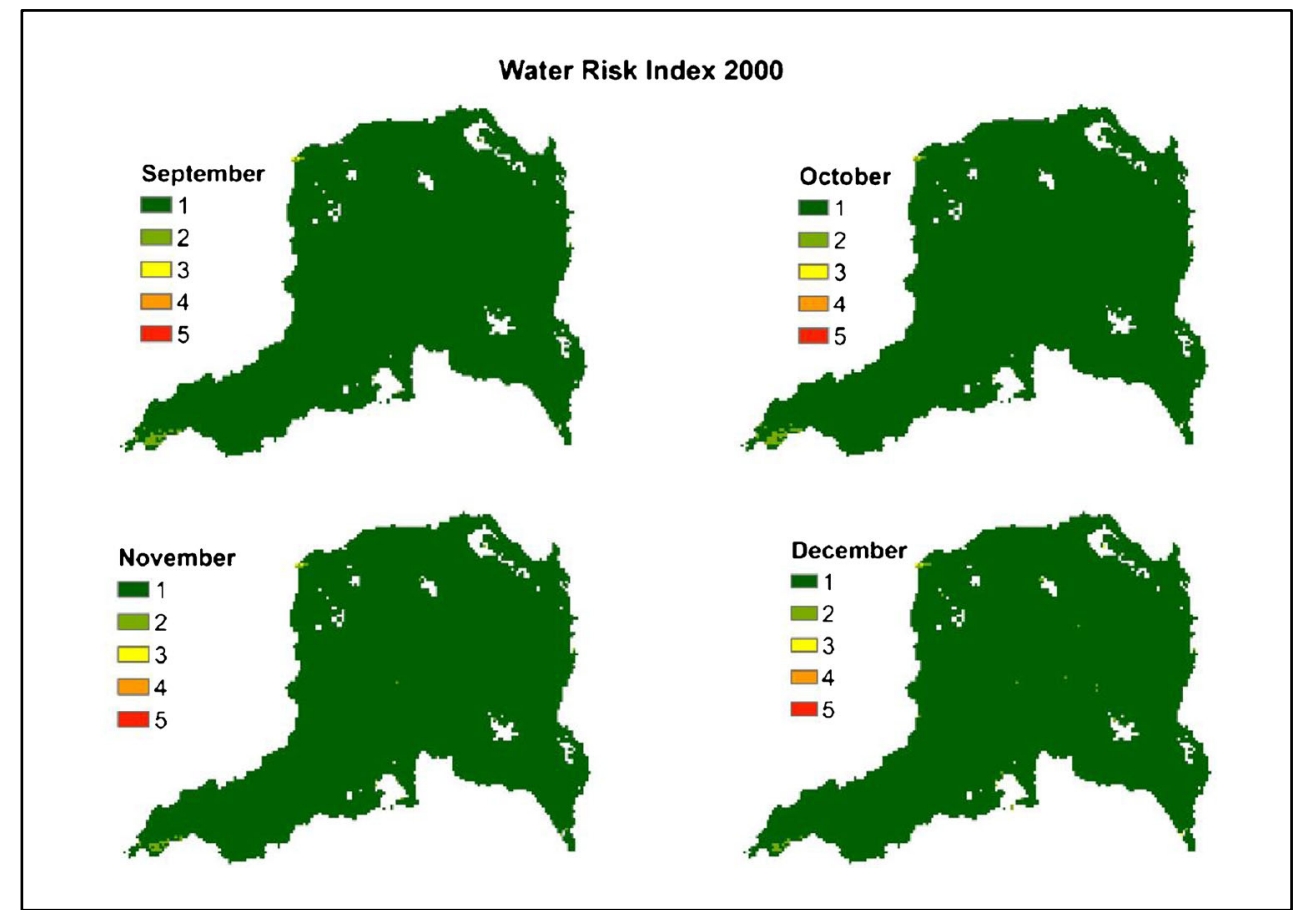


Fig. 11 Water risk index for the catchment between January and April for the year 2010

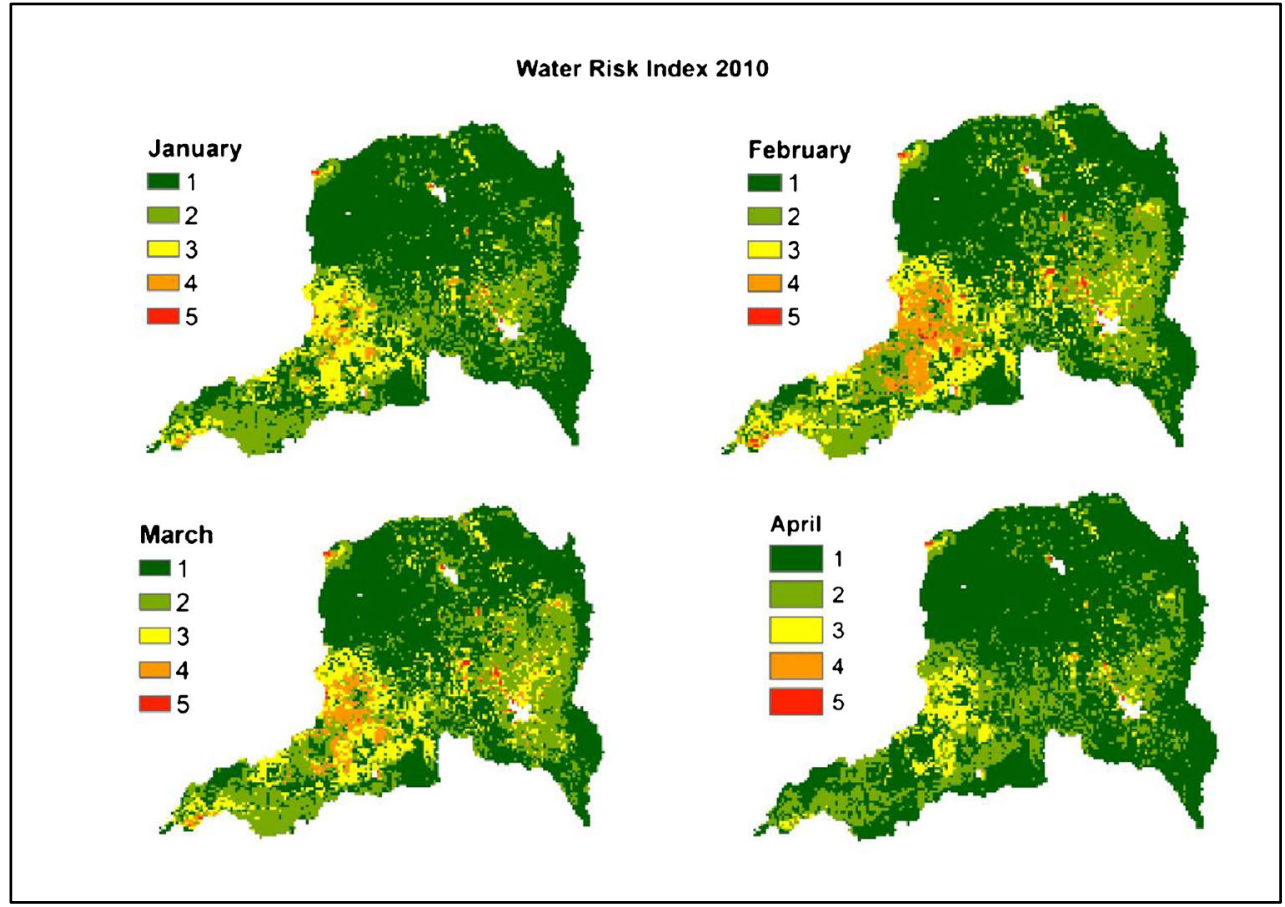

\section{Stakeholders priority}

Stakeholder priority was assigned based on their roles and their impact on the partnership and a total of four categories were defined: key stakeholders, primary stakeholders, secondary stakeholders, and undefined stakeholders. The key stakeholder is an actor that can impact the partnership extensively, a primary stakeholder is an actor that can advance or slow down the partnership, a secondary stakeholder is an actor that needs to understand the basics of the partnership, and the undefined stakeholder is an actor whose roles are not defined (IWaSP 2018). There are 11 key stakeholders who can drive the partnership and are
Fig. 12 Water risk index for the catchment between May and August for the year 2010

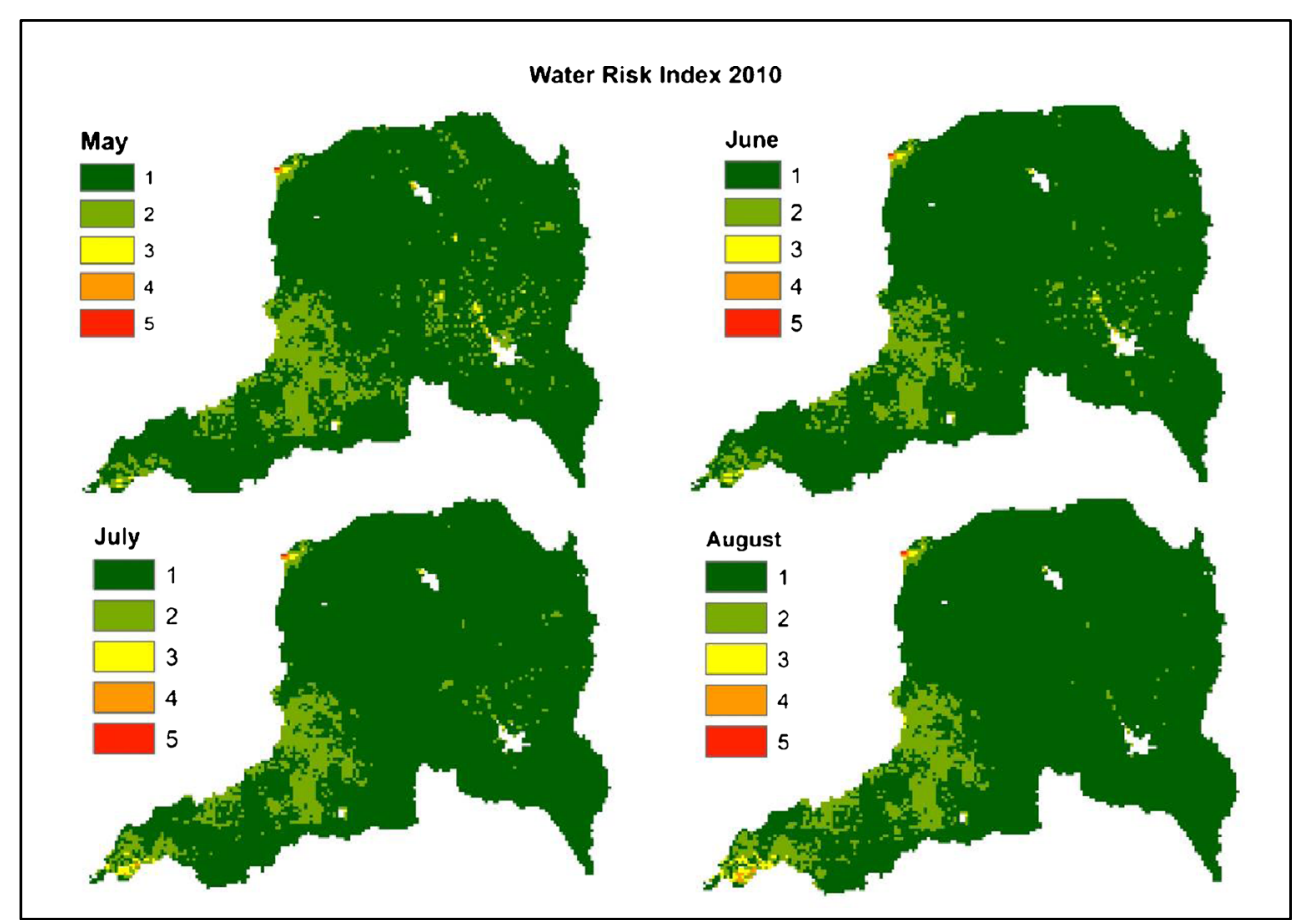


Fig. 13 Water risk index for the catchment September to December for the year 2010

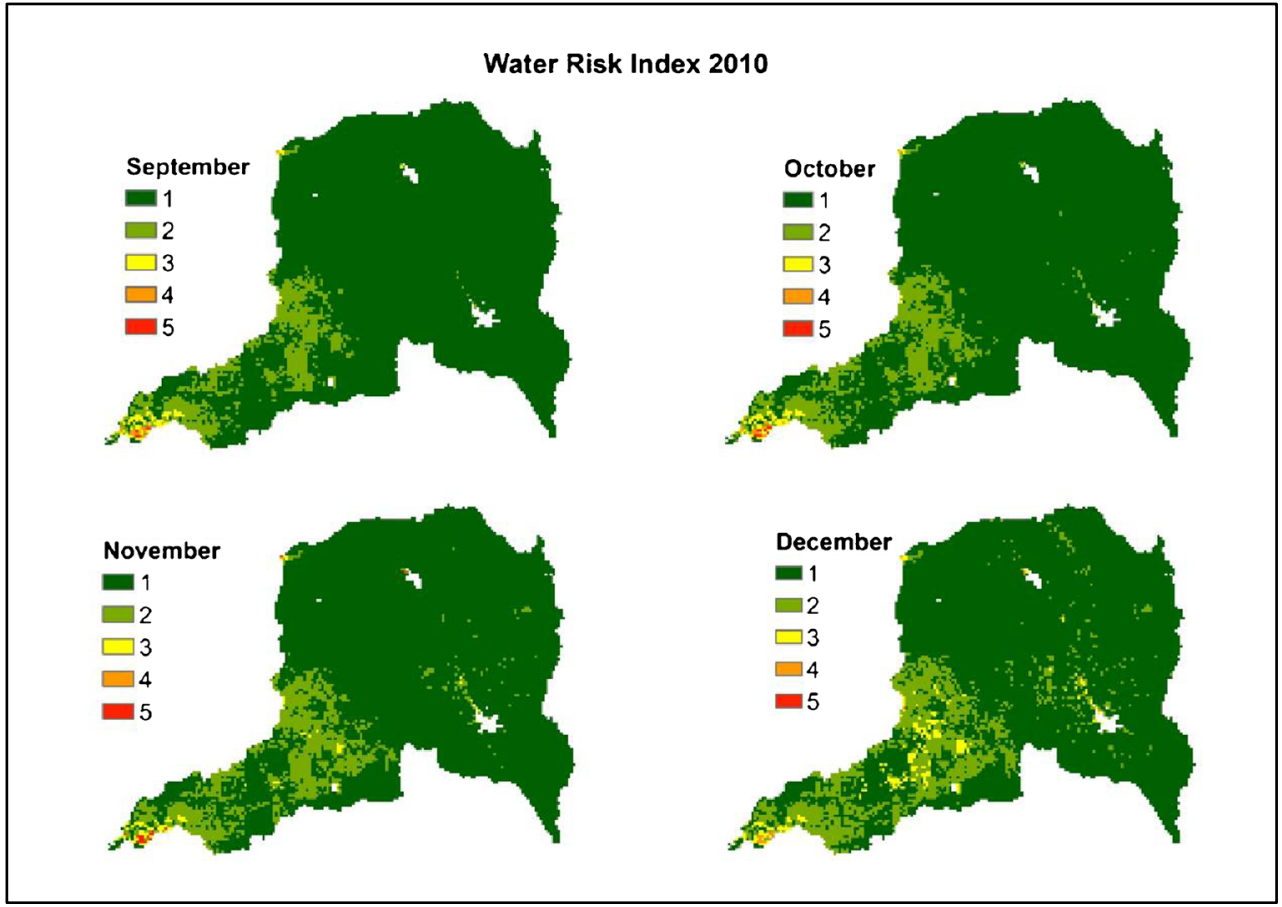

pivotal to the success of the partnership and 14 primary stakeholders who will advance the partnership to achieve the set targets and objectives and the majority of the stakeholders being the secondary stakeholders with up to 23 of the sampled stakeholders that need to undergo capacity building on the importance and the fundamentals of the partnership. The least of the stakeholder priority is the stakeholder with interests in water resources management, but their roles are not defined.

\section{Water stewardship partnership}

\section{Water stewardship program}

Interviewing the various stakeholders showed that there is a lack of water stewardship program within the river basin; however, all stakeholders were willing to participate in the water stewardship. Majority of the stakeholders $(88 \%)$
Fig. 14 Water risk index for the catchment between January and April for the year 2014

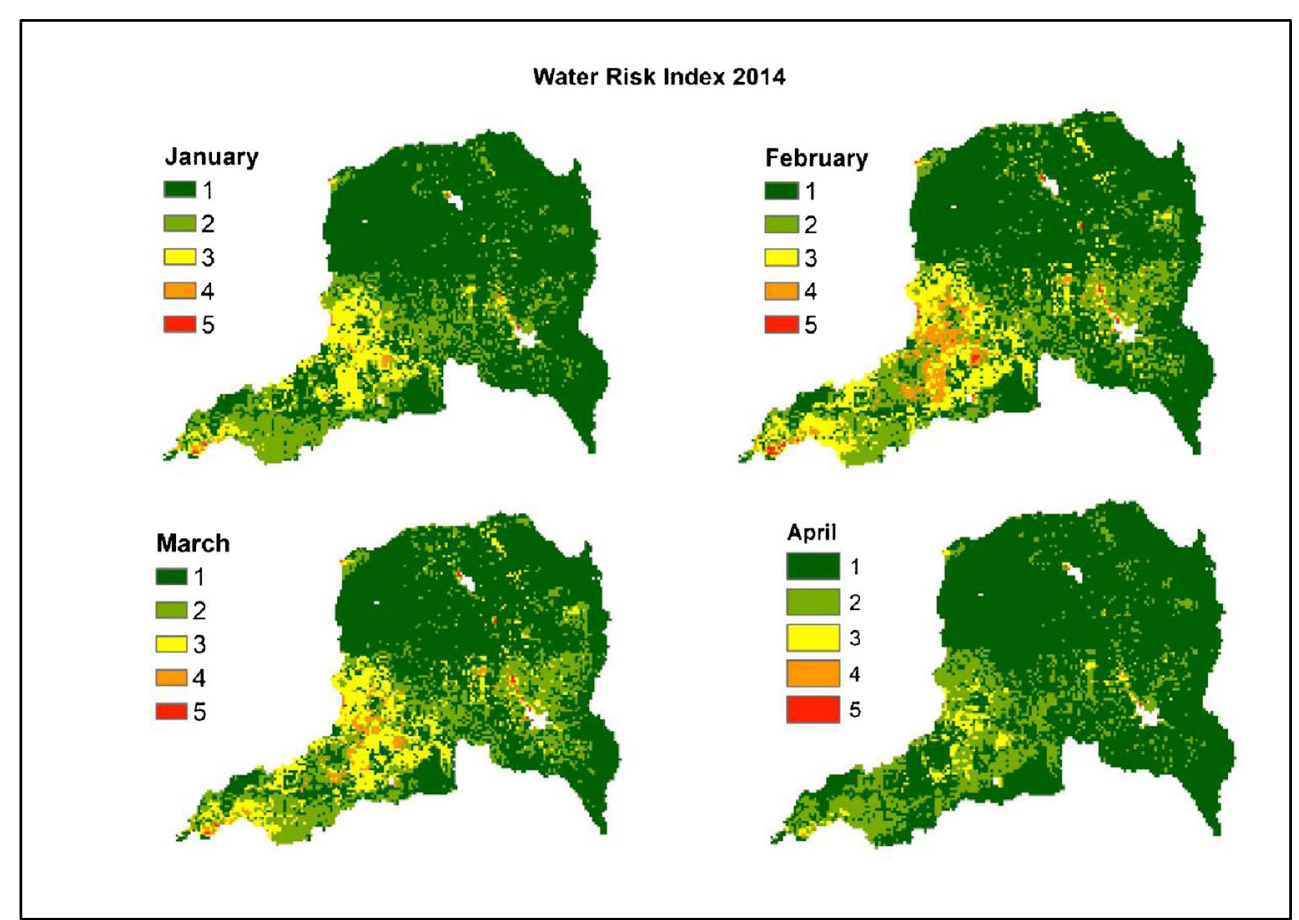


Fig. 15 Water risk index for the catchment between May and August for the year 2014

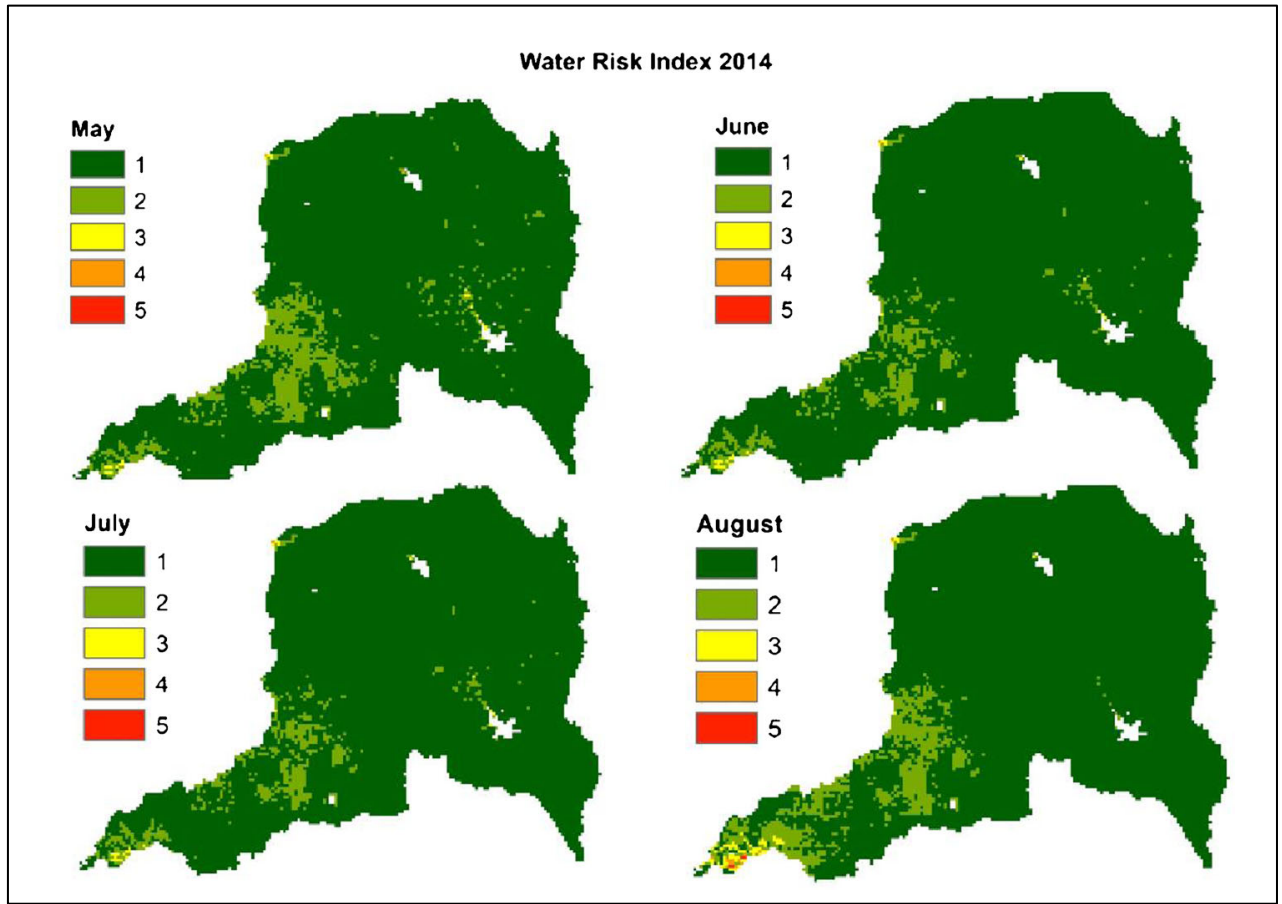

responded to a lack of stewardship program while $12 \%$ responded to a presence of a stewardship program. From the observation, it was clear that there was a lack of a clear strategy to bring water stakeholders onboard as a single platform to carry out activities that can reduce water risks in the river basin.

\section{Water shortage observation}

Stakeholders acknowledged that there were water shortages observed within the river basin and attributed the causes to human activities, natural variability, and climate change. A minority of the respondents, $27 \%$, believed that the changes
Fig. 16 Water risk index for the catchment between September to December for the year 2014

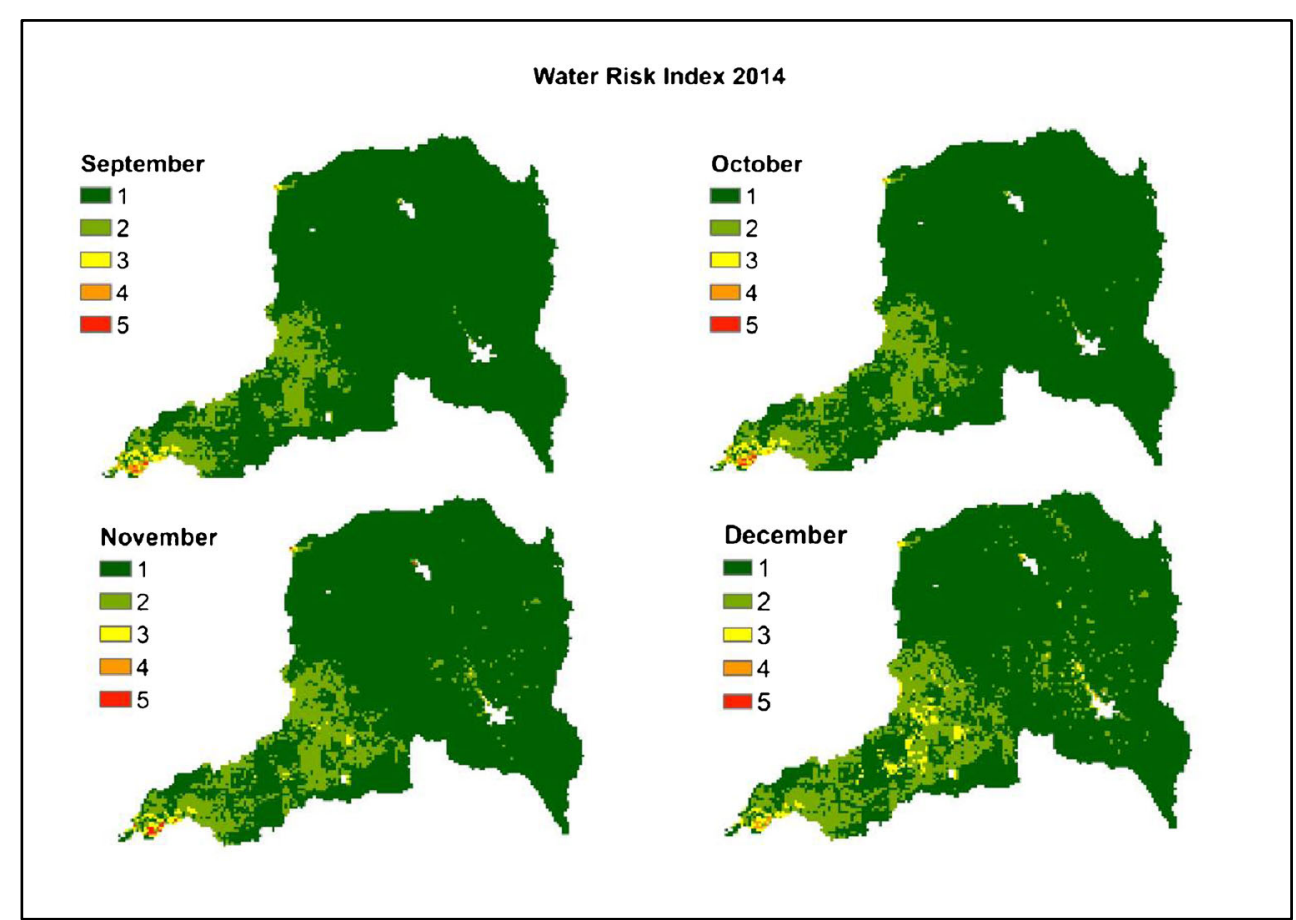


Table 2 Stakeholder categories from stakeholder mapping

\begin{tabular}{ll}
\hline Category & Number of stakeholders \\
\hline Government authorities & 7 \\
International organization & 2 \\
Local NGO & 3 \\
Company & 4 \\
Academia & 3 \\
Local community & 5 \\
Water user & 10 \\
Parastatal & 8 \\
Private sector & 10 \\
Total & 52 \\
\hline
\end{tabular}

were due to climate change but $94 \%$ believed that the human activities had brought about the changes.

\section{Watershed protection activities}

Currently, there are several catchment protection activities that involved the stakeholders in the study area, including tree planting, riparian land protection, soil erosion control, wetland restoration, reforestation, and capacity building. All stakeholders are involved in tree planting except one international organization, with the capacity building being done by $65 \%$ of the stakeholders interviewed. Forty-six percent of the stakeholders have been involved in reforestation and $21 \%$ involved in wetland restoration with less than $20 \%$ of the stakeholders being involved in riparian land protection and soil erosion control.

\section{Stewardship activities likely to be involved}

Majority of the stakeholders were willing to participate in the conservation activities ( $71 \%$ ) within the basin, capacity building $(61.5 \%)$ during stewardship activities, and catchment management activities (46.2\%) while $36.5 \% \%$ are willing to be involved in restoration activity with only $26.9 \%$ ready to be involved in protection activities.

\section{Stewardship activity for catchment restoration}

The results showed that $(88.2 \%)$ of the stakeholders would be involved in reforestation activities in deforested areas. Eighty percent of the stakeholders would love to be involved in activities aiming at improving agricultural production and capacity building. Twenty-five percent of the stakeholders would be involved in wetland restoration, $31 \%$ in solid waste management, and $30 \%$ in catchment rehabilitation through soil erosion control among other activities.

\section{Stewardship activities for water risk prevention}

Stakeholders were interested in working together to reduce future water risks by carrying out activities such as water resources training, participation in workshops, and strengthening the monitoring and evaluation to assess the progress and effectiveness of the stewardship program. Riverbank protection, soil erosion prevention, RGS rehabilitation, and water quality/quantity monitoring are among activities that people are interested (Fig. 17).

\section{Monetary allocation}

Respondents were asked about their willingness to allocate funds for the stewardship program and $83 \%$ were willing to allocate funds for the stewardship activities.

\section{The expectation from the partnership}

Although all stakeholders were willing to work with others for the water stewardship and were willing to commit funds towards the partnership, they had expectations that they were looking forward to from the partnership and concerns that they felt might hinder the success of the partnership. Stakeholders' highest expectation from the partnership and other partners was for the program to achieve the set-out objectives $(82.4 \%)$ while ensuring inclusivity in decision-making (64.7\%) among partners. Commitment and transparency during the partnership were also emphasized by the partners with the need to engage other government officials with the least of their concerns being regular meetings and regular feedback.

\section{Conclusions}

This study was carried out in the Nzoia River Basin to assess the potential of water stewardship partnership using the Water Risk and Action Framework guide developed by IWaSP to provide guidance on stewardship. The study was guided by three objectives which were water risks assessment in the basin, stakeholder mapping, and assessment of the stewardship potential. The study methodology involved the use of remote sensing data for the water risk assessment and application of the ArcGIS computer program to derive and quantify the water risks, mapping of potential stakeholders using stakeholder template developed by IWaSP, and the primary data on stakeholders collected using questionnaires to assess their willingness to form a water stewardship partnership.

From the analysis, it was clear that the basin faces water risks with different magnitudes and this has been increasing since 2000. There was a spatial and temporal variation of risk in the river basin with the highest risks being 
Fig. 17 Stewardship activities for water risk prevention

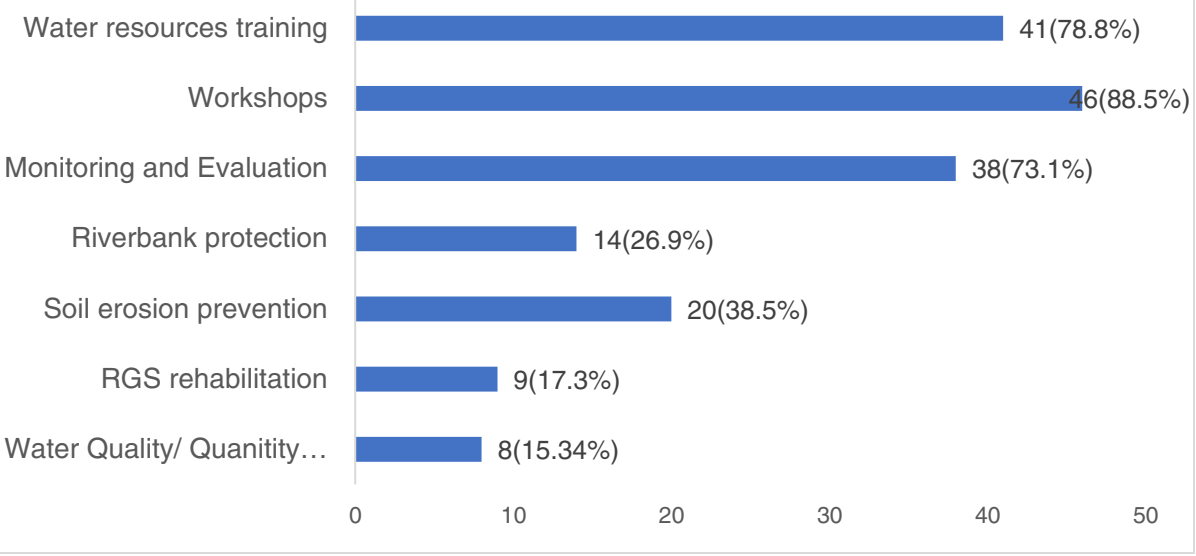

experienced in January, February, and March in the middle and lower catchment. There were constantly high risks towards the outlet of the river throughout the year attributed to low rainfall, low primary productivity, and high evapotranspiration rates. The catchment faces increased deforestation, land degradation, and land cover changes in the upper catchment while the middle part of the basin experiences low primary productivity caused by land degradation, deforestation, as well as clearing of land for agriculture and settlement.

Within NRB, there is a significant number of stakeholders from local, international, government, and private sector who have the potential to spearhead a water stewardship partnership and the majority are vital to the success of the stewardship. All water stakeholders are significant in the success of a stewardship program, but key stakeholder will advance the partnership. However, there is a need for capacity building of non-core stakeholders in order to bridge the knowledge gap and level the understanding of the importance of each stakeholder, their roles, and the importance of a water stewardship partnership.

Although there has been an observed water shortage that is attributed to both human activities, climate change, and the natural climatic variations, there lacks a platform that brings all stakeholders together with a goal of carrying out collective activities that reduce the water risks; therefore, there is a need for a systematic approach towards future water risk reduction. Although there are activities that are carried out for catchment protection and restoration, there is a need to harmonize activities since the majority of the stakeholders are willing to partner in reducing water risks and are positive in the implementation of programs for water risk reduction. With a water stewardship partnership being positively accepted, an objective oriented program is highly likely to be successful and the partnership should be built on transparency, commitment, and inclusivity. There is a potential for a water stewardship partnership in the river basin with the stakeholders willing to partner to reduce the future water risks.

Last but not least, the study showed that droughts, deforestation, and land degradation are the major challenges that are facing the RNB. Therefore, the following recommendations are suggested to mitigate these challenges: (1) Catchment protection, restoration measure should be put in place by integration the different sector and partners such as agricultural, industrial, environment, and urban planning whose activities cumulatively has an effect of the quality or quantity of water; (2) there is a need for reforestation of the catchment, climate change mitigation, and combat land degradation to minimize the future water risks; and (3) formation of an inclusive, objective oriented partnership involving all stakeholders in the water sector with intervention activities be implemented at WRUA levels focusing on the sub-catchment level.

This study is significant to water managers, non-water experts and policy makers since it proposes a simplified method for water risk analysis at basin level by using simple analysis tools and secondary data. LAI, RUE, PAC, and SWS are readily available and require simplified data manipulation in a GIS environment to quantify risks. On water stewardship, the tools developed help managers to identify and group water stakeholders with interest in partnering to manage water resources. This will bring together stakeholders from different fields onto one table to discuss and prepare a roadmap on management of water resources through a series of activities. The study can be helpful in setting up water risks management projects at catchment level and sub-catchment level as the major causes of water risks are quantified and their locations identified. These can inform on specific decisions and activities to reduce risks. It is important to note that the study is highly depended on secondary data and the temporal range of the data varies. This study gives high-resolution risk assessment at basin and sub-basin level as opposed to other studies. However, there is need for further research that will incorporate catchment morphology and other parameters in water risk assessment. 
Acknowledgments Background research for this article was done in the context of master's thesis in water policy at PAUWES. Therefore, the authors thank the African Union Commission and GIZ for funding this research.

Open Access This article is distributed under the terms of the Creative Commons Attribution 4.0 International License (http:// creativecommons.org/licenses/by/4.0/), which permits unrestricted use, distribution, and reproduction in any medium, provided you give appropriate credit to the original author(s) and the source, provide a link to the Creative Commons license, and indicate if changes were made.

\section{References}

Achieng A, Raburu P, Kipkorir E, Ngodhe S, Obiero K, Ani-Sabwa J (2017) Assessment of water quality using multivariate techniques in river Sosiani, Kenya. Environ Monit Assess 189(6):280

AfSIS (2015) Africa soil information Service. http://africasoils.net/. Accessed 21 Jan 2018

Atela, J, Quinn, C, Houdet, JR, \& Munang, P (2015). Policy coherences between global climate change rules and national sectoral policies: the case of REDD+ in Kenya. African Centre for Technology Studies (ACTS). Nairobi. 003/2015.

Ayehu GT, Tadesse T, Gessesse B, Dinku T (2018) Validation of new satellite rainfall products over the Upper Blue Nile Basin, Ethiopia. Atmos Meas Tech 11(4):1921-1936. https://doi.org/10.5194/amt11-1921-2018

Bai Y, Wu J, Xing Q, Pan Q, Huang J, Yang D, Han X (2008) Primary production and rain use efficiency across a precipitation gradient on the Mongolia plateau. Ecology 89(8):2140-2153

Behnsen F (2016) Mlalakua River Restoration Project (MRRP). https:// ceowatermandate.org/wraf/resources/. Accessed 4 May 2018

Bilskie J, Scientific C (2001) Soil water status: content and potential. Campbell Scientific, Inc App. Note: 2S-1 https://s.campbellsci.com/ documents/us/technical-papers/soilh20c.pdf. Accessed 21 Jan 2018

Buermann W, Wang Y, Dong J, Zhou L, Zeng X, Dickinson RE Potter CS, Myneni RB (2002) Analysis of a multiyear global vegetation leaf area index data set. J Geophys Res 107(4-14). https://doi.org/ 10.1029/2001JD000975

Burt BA (2001) Definitions of risk. J Dent Educ 65(10):1007-1008

Carrie V-S, Andrew A, Doug B, Beal ML, G.S.W. (2016) Building partnerships to scale up conservation: 4R Nutrient Stewardship Certification Program in the Lake Erie watershed. J Great Lakes Res 42(6):1395-1402. https://doi.org/10.1016/j.jglr.2016.09.004

CHG (2018) Climate hazards group data. Retrieved from http://chg.geog. ucsb.edu/data/chirps/\#pub. Accessed 25 July 2018

Choubin B, Solaimani K, Roshan MH, Malekian A (2017) Watershed classification by remote sensing indices: a fuzzy c-means clustering approach. J Mt Sci 14(10):2053-2063

Dai A, Fung IY, Del Genio AD (1997) Surface observed global land precipitation variations during 1900-88. J Clim 10(11):2943-2962

Darabi H, Choubin B, Rahmati O, Haghighi AT, Pradhan B, Kløve B (2019) Urban flood risk mapping using the GARP and QUEST models: a comparative study of machine learning techniques. J Hydrol 569:142-154

Dardel C, Kergoat L, Hiernaux P, Grippa M, Mougin E, Ciais P, Nguyen C-C (2014) Rain-use-efficiency: what it tells us about the conflicting Sahel greening and Sahelian paradox. Remote Sens 6(4):3446-3474

Dickinson RE (1984) Modeling evapotranspiration for three-dimensional global climate models. J Geophys Res: 58-72. https://doi.org/10. 1029/GMO29p00

Dickinson RE (1995) Land-atmosphere interaction. Reviews of Geophysics 33(S2):917-922. https://doi.org/10.1029/95RG00284
Du L, Mikle N, Zou Z, Huang Y, Shi Z et al (2018) Global patterns of extreme drought-induced loss in land primary production: identifying ecological extremes from rain-use efficiency. Sci Total Environ 628:611-620

Dulo SO, Odira PMA, Nyadawa MO, Okelloh BN (2010) Integrated flood and drought management for sustainable development in the Nzoia River Basin. NWSEJ. 13(2)

EEA (1999) Water stress. In: E. E. Agency (ed) Environment in the European Union at the turn of the century. Copenhagen, European Environment Agency

Farrington R (2016) Lusaka Water Security Initiative: Wellfield Protection Project Retrieved from http://ceowatermandate.org/ wraf/wp-content/uploads/sites/15/2017/07/IWaSP_Prepare_ Zambia_Lusaka_03.08.2017.pdf. Accessed 22 Feb 2018

Fisher JB, Tu KP, Baldocchi DD (2008) Global estimates of the landatmosphere water flux based on monthly AVHRR and ISLSCP-II data, validated at 16 FLUXNET sites. Remote Sens Environ 112(3): 901-919

Funk C, Peterson P, Landsfeld M, Pedreros D, Verdin J, Shukla S, Husak G, Rowland J, Harrison L, Hoell A, Michaelsen J (2015 $)$ The climate hazards infrared precipitation with stations - a new environmental record for monitoring extremes. Sci Data 2:150066. https:// doi.org/10.1038/sdata.2015.66

Funk C, Verdin A, Michaelsen J, Peterson P, Pedreros D, Husak G $\left(2015^{\mathrm{b}}\right)$ A global satellite-assisted precipitation climatology. Earth Syst Sci Data 7(2):275-287. https://doi.org/10.5194/essd-7-2752015

Gathagu JN, Isiah MJ, Oduor BO, Mourad KA (2017) Soil and water conservation in Thika-Chania catchment, Kenya. Int J Sustain Water Environ Syst 9(2):59-65

Gathagu JN, Mourad KA, Sang J (2018) Effectiveness of contour farming and filter strips on ecosystem services. Water 10(10):1312. https:// doi.org/10.3390/w10101312

Gholamhoseini M, Ghalavand A, Dolatabadian A, Jamshidi E, KhodaeiJoghan A (2013) Effects of arbuscular mycorrhizal inoculation on growth, yield, nutrient uptake and irrigation water productivity of sunflowers grown under drought stress. Agric Water Manag 117: 106-114. https://doi.org/10.1016/j.agwat.2012.11.007

GitHub (2010) AfSIS-at-CIESIN. Retrieved from https:/github.com/ AfSIS-at-CIESIN. Accessed 21 Mar 2018

Hoekstra AY (2017) Water footprint assessment in supply chains. Sustainable Supply Chains. Springer. 4: 65-85. https://doi.org/10. 1007/978-3-319-29791-0_4

Huemmrich K, Kinoshita G, Gamon J, Houston S, Kwon H, Oechel W (2010) Tundra carbon balance under varying temperature and moisture regimes. J Geophys Res 115(G00102):1-8 https://doi.org/10. 1029/2009JG001237,2010

INWaSP (2011) The Imarisha Naivasha Water Stewardship Programme (INWaSP). Retrieved from http://www.imarishanaivasha.or.ke/. Accessed 5 Feb 2018

IWaSP (2018) Water Risk \& Action Framework. Retrieved from https:// ceowatermandate.org/wraf/about/. Accessed 21 Dec 2017

Joab MJ, Khaemba A, Mburu N, Moses AN (2016) Effects of increased land use changes on runoff and sediment yield in the Upper River Nzoia catchment. Int J Civ Eng 7(2). Retrieved from https://www. iaeme.com/MasterAdmin/UploadFolder/IJCIET_07.../IJCIET_07 02_006.pdf. Accessed 20 Jan 2018

Jones $\bar{G}$ (2017) Building a water stewardship community in the UNESCO Western Port Biosphere Reserve, Victoria, Australia. Retrieved from https://a4ws.org/wp-content/uploads/2019/02/5AWS-and-Western-Port-Biosphere-2017-Bldg-a-WS-Community. pdf. Accessed 10 Mar 2018

Khajuria S (2016) Water, climate change and sustainable development: an industry example. Water Security, Climate Change and Sustainable Development: Springer. Singapore. 123-136. https://doi.org/10. 1007/978-981-287-976-9 
Kioko MJ (2013) Who stole the rain? The case of recent severe droughts in Kenya. Eur Sci J 9(5)

Kirugara D, Nevejan N (1996) Identification of pollution sources in the Kenyan part of the Lake Victoria catchment area, vol 78. Kenya Marine and Fisheries Research Institute, Kisumu, p 1996

Kundu A, Patel NR, Saha SK, Dutta D (2017) Desertification in western Rajasthan (India): an assessment using remote sensing derived rainuse efficiency and residual trend methods. Nat Hazards 86(1):297313. https://doi.org/10.1007/s11069-016-2689-y

Lambooy T (2011) Corporate social responsibility: sustainable water use. J Clean Prod 19(8):852-866

Li L, Hong Y, Wang J, Adler RF, Policelli FS, Habib S, Irwn D, Korme T, Okello L (2009) Evaluation of the real-time TRMM-based multisatellite precipitation analysis for an operational flood prediction system in Nzoia Basin, Lake Victoria, Africa. Nat Hazards 50(1): 109-123. https://doi.org/10.1007/s11069-008-9324-5

Lisar SY, Motafakkerazad R, Hossain MM, Rahman IM (2012) Water stress in plants: causes, effects and responses. Water stress: IntOpen. Retrieved from https://www.intechopen.com/books/water-stress/ water-stress-in-plants-causes-effects-and-responses. Accessed 10 Apr 2018

Malecki K, Schultz A, Severtson D, Anderson H, VanDerslice J (2017) Private-well stewardship among a general population based sample of private well-owners. Sci Total Environ 601-602:1533-1543. https://doi.org/10.1016/j.scitotenv.2017.05.284

Marshall S (2011) The water crisis in Kenya: causes, effects and solutions. Global Majority E-Journal 2(1):31-45

Mathevet R, Bousquet F, Raymond CM (2018) The concept of stewardship in sustainability science and conservation biology. Biol Conserv 217:363-370. https://doi.org/10.1016/j.biocon.2017.10. 015

Metobwa OGM, Mourad KA, Ribbe L (2018) Water demand simulation using WEAP 21: a case study of the Mara River Basin, Kenya. Int J Nat Resour Ecol Manag 3(1):9-18. https://doi.org/10.11648/j. ijnrem.20180301.12

Miller T, Goodling E, Herrington C, Devlin J (2015) The Community Watershed Stewardship Program: experiments in engagement and equity in Portland, OR. Curr Opin Environ Sustain 17:30-35. https://doi.org/10.1016/j.cosust.2015.08.008

MoF\&W (2013) Analysis of drivers and underlying causes of forest cover change in the various forest types of Kenya. Nairobi, Kenya. Retrieved from http://www.kenyaforestservice.org/documents/ redd/Analysis $\% 20 \% 20$ of $\% 20$ Drivers $\% 20$ of $\% 20$ Deforestation $\%$ 20\&forest $\% 20$ Degradation\%20in\%20Kenya.pdf. Accessed 20 Feb 2018

Munyao JM, Kimiti JM, Gikuma-Njuru P (2017) Water pollution in a riparian community: the case of river Athi in Makueni County, Kenya. Retrieved from http://www.journalrepository.org/media/ journals/JALSI_40/2017/Feb/Munyao1032017JALSI31436_1.pdf. Accessed 30 Mar 2018

Myneni RB, Los SO, Tucker CJ (1996) Satellite-based identification of linked vegetation index and sea surface temperature anomaly areas from 1982-1990 for Africa, Australia and South America. Geophys Res Lett 23(7):729-732

NASA (2014) USGS Land Processing Distributed Active Archive Center. Retrieved from: https://lpdaac.usgs.gov/. Accessed 21 Jan 2018

Odira PM, Nyadawa M, Ndwallah BO, Juma N, Obiero J (2010) Impact of land use/cover dynamics on streamflow: a case of Nzoia River Catchment, Kenya. Nile Basin Water Sci Eng J 3(2):64-78

Olson E, Prepscius J, Baddache F (2011) Stakeholder mapping. In B. f. S. Responsibility (Ed.)

Orr S, Cartwright A, Tickner D (2009) Understanding water risks A primer on the consequences of water scarcity for government and business. WWF Water Security Series 4. Retrieved from: https://
www.wwf.de/fileadmin/fm-wwf/Publikationen-PDF/WWF_ understanding water risk.pdf. Accessed 20 Dec 2018

Parr M (2017) Improved community livelihoods and sustainable water management in the River Rwizi Catchment. Retrieved from http:// ceowatermandate.org/wraf/wp-content/uploads/sites/15/2017/07/ IWaSP_ACT_Uganda-River-Rwizi_17.05.2017.pdf. Accessed 12 Jan 2018

Penman, H. L. (1948). Natural evaporation from open water, bare soil and grass. Proc Royal Soc Lond 193(1032):120-145

Peter J, David H, Daphne C (2015) Water stewardship and corporate sustainability: a case study of reputation management in the food and drinks industry. J Public Relat Res 15(1): $116-126$

Priestley CHB, Taylor RJ (1972) On the assessment of surface heat flux and evaporation using large-scale parameters. Mon Weather Rev 100(2):81-92. https://doi.org/10.1175/1520-0493(1972)100<0081: otaosh $>2.3 . c 0 ; 2$

Ran AM (2017) Upper-Athi Water Stewardship Partnership Retrieved from http:/ceowatermandate.org/wraf/wp-content/uploads/sites/15/ 2017/07/IWaSP_Prepare_Kenya_Kiambu_03.07.2017.pdf. Accessed 12 Jan 2018

Reed M, Curzon R (2015) Stakeholder mapping for the governance of biosecurity: a literature review. J Integr Environ Sci 12(1):15-38

Ruiz-Frau A, Edwards-Jones G, Kaiser MJ (2011) Mapping stakeholder values for coastal zone management. Mar Ecol Prog Ser 434:239_ 249

Ruppert JC, Holm A, Miehe S, Muldavin E, Snyman HA, Wesche K, Linstädter A (2012) Meta-analysis of ANPP and rain-use efficiency confirms indicative value for degradation and supports non-linear response along precipitation gradients in drylands. J Veg Sci 23(6): $1035-1050$

Sajedi-Hosseini F, Malekian A, Choubin B, Rahmati O, Cipullo S, Coulon F, Pradhan B $\left(2018^{\mathrm{a}}\right)$ A novel machine learning-based approach for the risk assessment of nitrate groundwater contamination. Sci Total Environ 644:954-962

Sajedi-Hosseini F, Choubin B, Solaimani K, Cerdà A, Kavian A $\left(2018^{\mathrm{b}}\right)$ Spatial prediction of soil erosion susceptibility using a fuzzy analytical network process: application of the fuzzy decision making trial and evaluation laboratory approach. Land Degrad Dev 29(9):3092 3103

SD (2018). Deloitte cautioned that Nairobi risks facing water shortage Standard Digital. Retrieved from: https://www.standardmedia.co.ke/ business/article/2001270110/packed-diary-for-incoming-water-cssimon-chelugui. Accessed 12 Feb 2018

Sellers P, Dickinson R, Randall D, Betts A, Hall F, Berry J, Nobre, C (1997) Modeling the exchanges of energy, water, and carbon between continents and the atmosphere. Science, 275(5299), 502-509

Shepheard M, Norer R (2013) Increasing water stewardship responsibility: water protection obligations and the watershed management policy affecting farmers in Lucerne, Switzerland. Environ Law 15(2):121-138

Sheppard JC, Ryan CM, Blahna DJ (2017) Evaluating ecological monitoring of civic environmental stewardship in the Green-Duwamish watershed, Washington. Landsc Urban Plan 158:87-95. https://doi. org/10.1016/j.landurbplan.2016.09.017

Simpson P (2014) Water stewardship in the twenty-first century. Nat Clim Chang 4:311-313. https://doi.org/10.1038/ nclimate 2217

Smith K, Verberne O, Stuart O, Sánchez-Navarro R, Schmidt G, SeizPuyuelo R, Verberne J (2011) Assessing water risks: a practical approach for financial institutions. Retrieved from https://www. researchgate.net/publication/312318837_Assessing_water_risk_A practical approach for Financial Institutions. Accessed $1 \overline{3}$ Apr 2018 
Stuart O, Anton C, Dave T (2009) Understanding water risks: a primer on the consequences of water scarcity for government and business. Retrieved from https://www.wwf.de/fileadmin/fm-wwf/ Publikationen-PDF/WWF_understanding_water_risk.pdf. Accessed 30 Dec 2018

Sun J, Du W (2017) Effects of precipitation and temperature on net primary productivity and precipitation use efficiency across China's grasslands. GIScience \& Remote Sensing 54(6):881-897. https://doi.org/10.1080/15481603.2017.1351147

Taugourdeau S, le Maire G, Avelino J, Jones JR, Ramirez LG, Jara Quesada M, Charbonnier F, Gómez-Delgado F, Harmand JM, Rapidel B, Vaast P, Roupsard O (2014) Leaf area index as an indicator of ecosystem services and management practices: an application for coffee agroforestry. Agric Ecosyst Environ 192:19-37. https://doi.org/10.1016/j.agee.2014.03.042

Tongco MDC (2007) Purposive sampling as a tool for informant selection. Ethnobot Res Appl 5:147-158

Toté C, Patricio D, Boogaard H, van der Wijngaart R, Tarnavsky E, Funk C (2015) Evaluation of satellite rainfall estimates for drought and flood monitoring in Mozambique. Remote Sens 7(2):1758-1776

Trabucco A, Zomer RJ (2010) Global Soil Water Balance Geospatial Database. Retrieved from https://www.cgiar-csi.org. Accessed 30 Mar 2018
Vance-Borland K, Holley J (2011) Conservation stakeholder network mapping, analysis, and weaving. Conserv Lett 4(4):278-288

Veldkamp TIE, Wada Y, Aerts JCJH, Ward PJ (2016) Towards a global water scarcity risk assessment framework: incorporation of probability distributions and hydro-climatic variability. Environ Res Lett 11(2):024006

VM (2018) Risk calculators and dashboards. Lack of stable supplies may lead to future oil price hikes and regional unrest. Retrieved from https://www.maplecroft.com/about/news/water_security.html. Accessed 15 May 2018

WRA (2018) Water resources data. Retrieved from https://www.wra.go. $\mathrm{ke} /$. Accessed 12 June 2018

WWF (2013) Water Stewardship 2013 Brief: perspectives on business risks and responses to water challenges. Retrieved from http://wwf. panda.org/?210092/Water-Stewardship\%2D\%2DPerspectives-onbusiness-risk-and-responses \% 2D\%2Dto-water-challenges. Accessed 20 Apr 2018

WWF, KFW (2018) The water risk filter. Retrieved from http://waterriskfilter. panda.org/en/Assessment\#WaterRiskAssessmentTab/facility/992. Accessed 21 Jan 2018

Zhao Y, Wang X, Vázquez-Jiménez R (2018) Evaluating the performance of remote sensed rain-use efficiency as an indicator of ecosystem functioning in semi-arid ecosystems. Int J Remote Sens 39(10): $3344-3362$ 